\title{
1 Experimental Platform to Facilitate Novel Back Brace Development for the 2 Improvement of Spine Stability
}

3 L. Cooper ${ }^{1}$, A. Gullane ${ }^{1}$, J. Harvey ${ }^{1}$, A. Hills ${ }^{1}$, M. Zemura ${ }^{1}$, J. Martindale ${ }^{2}$, A.

4 Rennie $^{1}$, D. Cheneler ${ }^{1}$

5

The spine or 'back' has many functions including supporting our body frame whilst facilitating movement, protecting the spinal cord and nerves and acting as a shock absorber. In certain instances, individuals may develop conditions that not only cause back pain but also may require additional support for the spine. Common movements such as twisting, standing and bending motions could exacerbate these conditions and intensify this pain. Back braces can be used in certain instances to constrain such motion as part of an individual's therapy and have existed as both medical and retail products for a number of decades. Arguably, back brace designs have lacked the innovation expected in this time. Existing designs are often found to be heavy, overly rigid, indiscrete and largely uncomfortable. In order to facilitate the development of new designs of back braces capable of being optimised to constrain particular motions for specific therapies, a numerical and experimental design strategy has been devised, tested and proven for the first time. The strategy makes use of an experimental test rig in conjunction with finite element analysis simulations to investigate and quantify the effects of back braces on flexion, extension, lateral bending and torsional motions as experienced by the human trunk. This paper describes this strategy and demonstrates its effectiveness through the proposal and comparison of two novel back brace designs.

Keywords: additive manufacturing, back braces, spine, finite element analysis, medical design

\section{Introduction}

The single largest cause of disability internationally is back pain, with lower back pain 
having a prevalence of $9.4 \%$ globally (Hoy, et al., 2014). This has a significant economic impact with 149 million working days lost per year globally due to lower back pain (Office for National Statistics, 2017). The modern way of life is a major contributing factor, with poor posture, an aging population and a sedentary lifestyle all leading to an increased risk (Morl \& Bradl, 2013) (Woolf \& Pfleger, 2003). Similarly, there exists a plethora of medical conditions affecting the spine (Woolf \& Pfleger, 2003).

Whilst some conditions benefit from free movement, others benefit from constraint to support the back and reduce pain. For instance, back braces limit the motion of the spine to stabilise weak, injured or fractured vertebrae and prevent progression of spinal deformity (Hawkinson, 2016) (Kawaguchi, et al., 2002). The extent of motion restriction could be of great interest and importance. Current brace designs can reduce trunk motion sufficiently to prevent pain or further injury for the prescribed recovery time whilst allowing the wearer to carry out some thoracolumbar motion (Cholewicki, et al., 2007). Where designs fall short is in restricting specific trunk motion, i.e. restriction limited just to lateral bending, for instance. As some musculoskeletal back conditions actually benefit from movement (Longo, et al., 2012), targeted restriction, as compared to gross restriction, deserves further investigation.

In addition, prolonged wear of rigid back braces can lead to substantial muscle mass loss due to reliance on the brace to impede motion (Eisinger, et al., 1996). Current designs restrict muscle recruitment in brace conditions inducing further problems for the patient. Research into soft braces largely indicates no modification to abdominal and trunk muscles if the

50 prescribed wearing period is adhered to (Fayolle-Minon \& Calmels, 2008) (Cholewicki, et al., 2010). The inverse relationship that exists between the extents of muscle restriction against comfort of the brace attributes to the difficulty in gauging the effect of prolonged wear of rigid braces (Hsu, et al., 2008). 
54 Two methods of measuring motion of the spine are employed in the literature and subsequently can be applied to test the effectiveness of back braces: biomechanical models (Ivancic, et al., 2002), and through electromyography (EMG) data from live healthy subjects in brace conditions (Cholewicki, et al., 2007) (Cholewicki, et al., 2010) (Lariviere, et al., 2014). Cholewicki et al. (Cholewicki, et al., 1995) conducted experiments on subjects in the upright standing posture position and performed near maximal ramp contraction, which is the body moving from rest to the maximum angle it can bend in flexion, extension and lateral bending, in each case checking the extent of muscle recruitment of torso muscles for spine stability. However, due to ethical issues with regards to access of patient data or use of live subjects, no current reliable methods exist to test the effectiveness of back braces. This research aims to address the shortcomings of the current design process and provide a method of assessing back braces quantifiably.

In this work, the design and operation of an experimental test rig for the quantified design, comparison and optimisation of back braces is described, hence providing a method for the braces to be more easily and ethically tested. The test rig incorporates an artificial spine and torso, shown here to be mechanically equivalent to a human torso. In order to prove its effectiveness, two novel back brace designs have been tested on the rig. It has been shown that by using the test rig, it is possible to quantify the reduction in flexion, extension, lateral bending and torsion.

The test rig, including spine, torso and brace design have been modelled using finite element analysis (FEA). This analysis allows for the study of spine motion during brace development. Through comparison to studies found in the literature, the validation simulations presented show that the simplified geometry, constraints and engineering materials used here have a mechanical response similar to equivalent components found in the human torso. Many 
complex FEA models of the spine exist, however only particular segments relevant to the area of study are usually created, hence the movement of a detailed full spine model has never been fully investigated in FEA (Huynh, et al., 2012) (Carboni \& Dal Pozzo, 2017), especially with the consideration of the full torso and many of the soft tissue therein. However recent advances in complete musculoskeletal models of the human spine in multibody dynamic simulations, which could be incorporated into FEA models, should be noted (Bayoglu, et al., 2019). The spine material models employed throughout previous work varies tremendously, with the intervertebral discs often modelled as simple cylinders between spinal vertebrae (Kurutz, 2010). It is common to split the vertebrae into both cortical and cancellous bone, and the intervertebral discs into nucleus pulposus and annulus fibrosus sections. Additionally, ligaments are commonly found within FEA spine models and the muscle systems seldom modelled. Here, a FEA model of the spine and torso is described and it is shown how these simulations can facilitate back brace development.

\section{Methods}

\section{Experimental Rig Design}

The artificial spine and torso used on the test rig was developed using FEA to ensure it was mechanically equivalent to a human torso. The spine geometry developed was that of an average adult male. Dimensions were found through analysing studies undertaken by Panjabi et al. (Panjabi, et al., 1992), who used CT scans of a cadaver to determine the curvature of the

97 spine and quantitatively describe the surface anatomy of 60 lumbar vertebrae. A simplified computer-aided design (CAD) model, shown in 


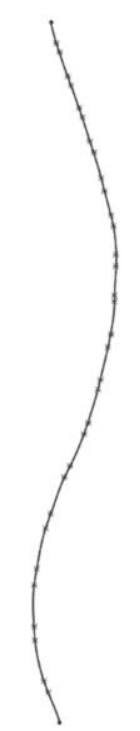

Guide Curve

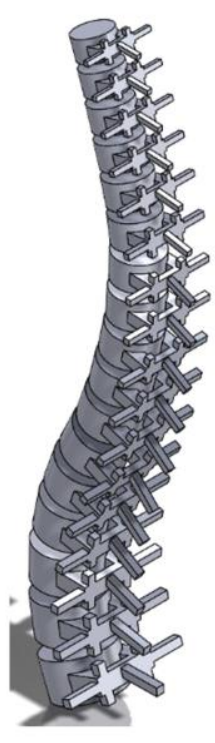

1. Vertebrae (Cortical)

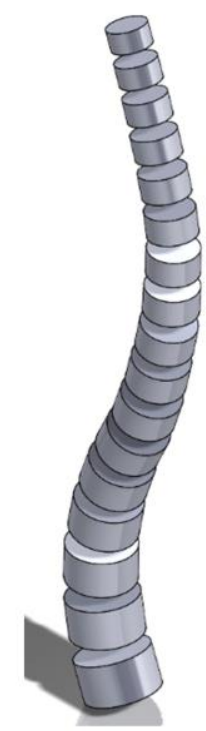

2. Vertebrae (Cancellous)

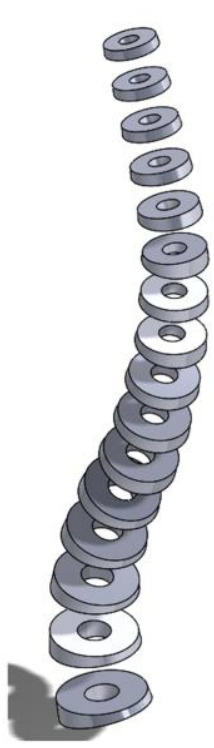

3. Disc (Annulus)

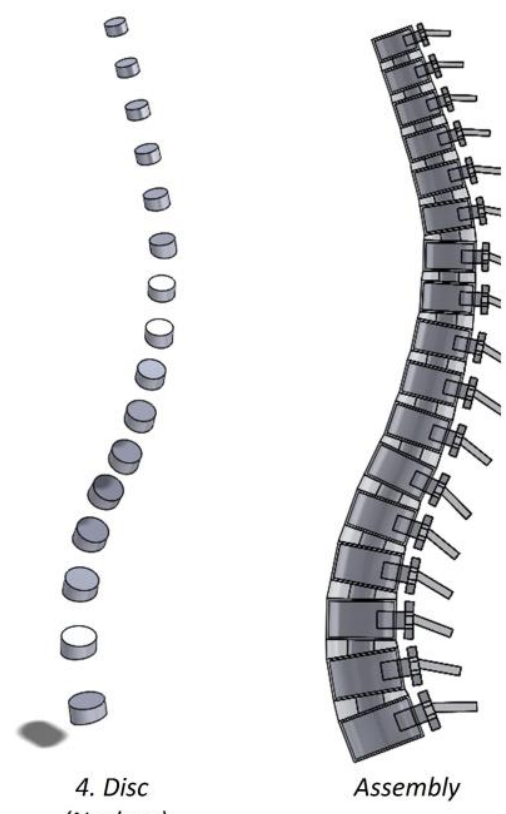

100 Figure 1, was then created for use within the study.

101

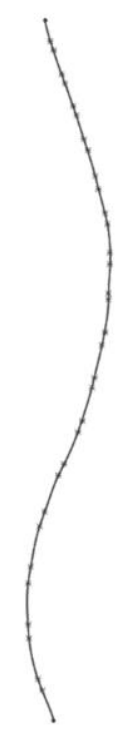

Guide Curve

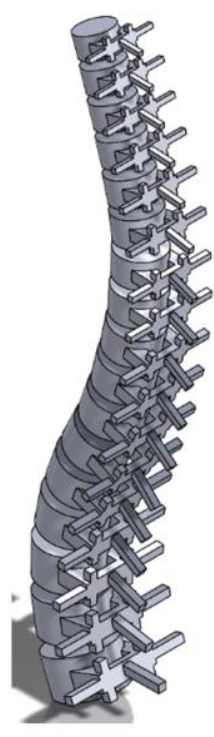

1. Vertebrae (Cortical)

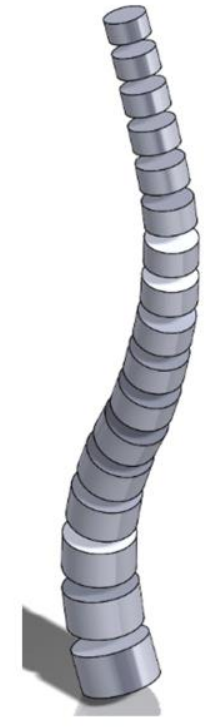

2. Vertebrae (Cancellous)

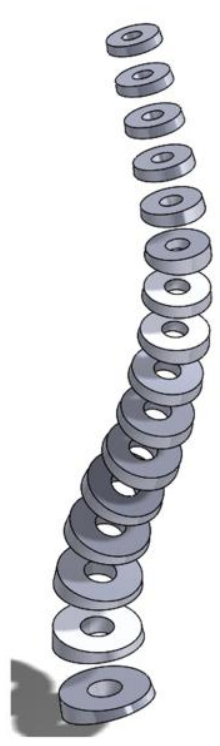

3. Disc

(Annulus)

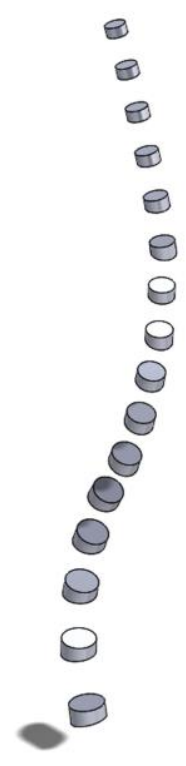

4. DisC (Nucleus)

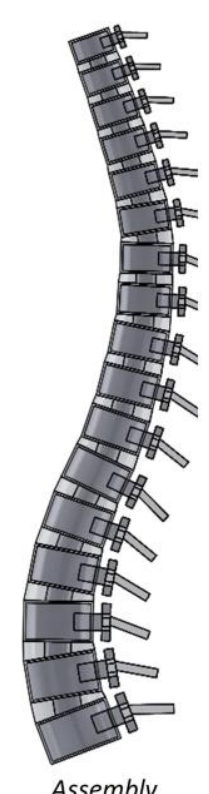

Assembly

Figure 1 - Breakdown of parts present within the spine CAD model

104 The CAD assembly permitted the breakdown of the spine into its constituent parts, which

105 allowed separate material models to be applied to each. The Mooney-Rivlin two-parameter

106 model was chosen to represent the discs, a model which predicts the behaviour of 
107 hyperelastic materials through curve fitting to data and used in numerous past studies

108 (Gómez, et al., 2017) (Wagnac, et al., 2011) (Schmidt, et al., 2006) (Dreischarf, et al., 2014).

109 The elastic modulus of vertebrae ranges from 1.5 to $3 \mathrm{GPa}$ (Swamy, 2014), and so ABS1400

110 with an Young's modulus of $1.68 \mathrm{GPa}$ (Ultimaker, 2017) was selected to represent bone

111 within the spine structure. Ligaments were modelled as tension-only springs and defined

112 through a particular stiffness (Pitzer, et al., 2016). Compressive testing of flexible

113 polyurethane foam samples yielded an elastic modulus of $0.128 \mathrm{MPa}$, within the limits stated

114 by Bonnaire et al. (Bonnaire, et al., 2014) for the human abdomen (0.01 to $1 \mathrm{MPa}$ ). Due to

115 the suitable elastic modulus, low cost and ease of use, it was selected to represent body mass

116 and soft tissue within the test rig torso.

117 Table 1 provides a breakdown of the material properties.

118 Table 1 - Material property data

\begin{tabular}{|c|c|c|c|c|}
\hline Part & Material Model & Modulus [MPa] & $\begin{array}{c}\text { Poisson's Ratio } \\
\text { v }\end{array}$ & Reference \\
\hline \multicolumn{5}{|l|}{ Accurate Model } \\
\hline Cortical Bone & Linear Isotropic & 5000 & 0.3 & $\begin{array}{l}\text { (Rohlmann, } \\
\text { et al., 2006) }\end{array}$ \\
\hline Cancellous Bone & Linear Isotropic & 10 & 0.2 & $\begin{array}{l}\text { (Kurutz, } \\
\text { 2010) }\end{array}$ \\
\hline Annulus Fibrosus & Mooney-Rivlin & $\begin{array}{l}\mathrm{C} 1=0.14, \mathrm{C} 10=0.56, \\
\mathrm{D}=0.143\end{array}$ & & $\begin{array}{l}\text { (Gómez, et } \\
\text { al., 2017) }\end{array}$ \\
\hline Nucleus Pulposus & Mooney-Rivlin & $\begin{array}{l}\mathrm{C} 1=0.03, \mathrm{C} 10=0.12, \\
\mathrm{D}=0.067\end{array}$ & & $\begin{array}{l}\text { (Gómez, et } \\
\text { al., 2017) }\end{array}$ \\
\hline Ligaments & Spring Elements & & & $\begin{array}{c}\text { (Pitzer, et al., } \\
2016)\end{array}$ \\
\hline \multicolumn{5}{|l|}{ Test Rig } \\
\hline ABS1400 (Vertebrae) & Linear Isotropic & 1681.5 & 0.3 & $\begin{array}{l}\text { (Ultimaker, } \\
\text { 2017) }\end{array}$ \\
\hline Soft Polyurethane Foam (Torso) & Linear Isotropic & 0.128 & 0.3 & \\
\hline Hard Polyurethane Foam (Discs) & Linear Isotropic & 5 & 0.3 & $\begin{array}{l}\text { (Seo, et al., } \\
\text { 2013) }\end{array}$ \\
\hline
\end{tabular}

119

120 In order to benchmark the effect of the geometry and constraints in the artificial spine model

121 used here against that of an actual human spine, the maximum displacement of the L2, L3

122 and L4 vertebrae were examined using the mechanical properties of human tissue and 
123 compared against studies undertaken by Wang et al. (Wang, et al., 2006). In that study, and

124 replicated here, a moment of $10 \mathrm{Nm}$ was applied upon the superior surface of the L2 body,

125 and the inferior surface of the L4 body was fixed. This is the maximum load that the spine

126 can withstand before any spinal injury is caused (Yamamoto, et al., 1989). Each loading

127 condition is displayed in

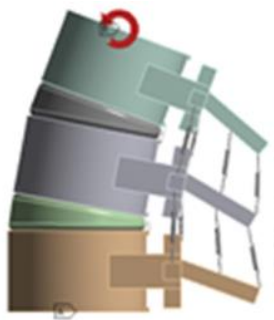

Flexion

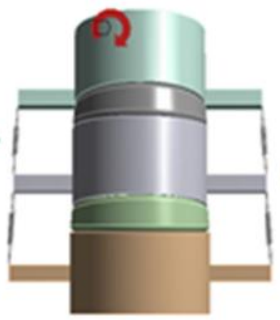

Left Lateral Bending

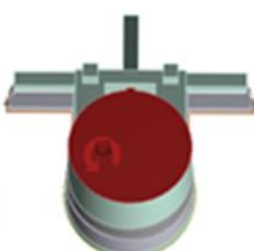

Torsion

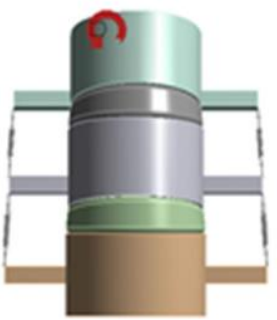

Right Lateral Bending

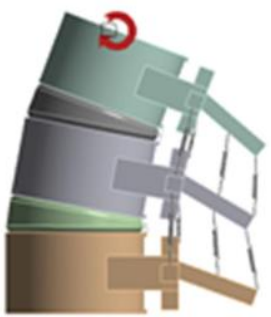

Extension

Figure 2

129 and the comparative results given in Table 2. The data shows that there is a reasonable

130 equivalency in the mechanical response between the geometry and constraints used in the

131 spine model here and those found in an actual human spine.

132

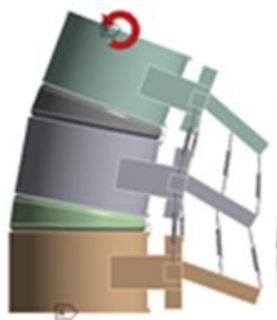

Flexion

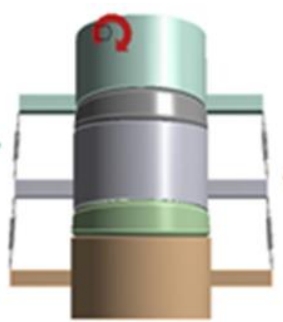

Left Lateral Bending

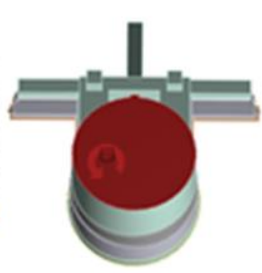

Torsion

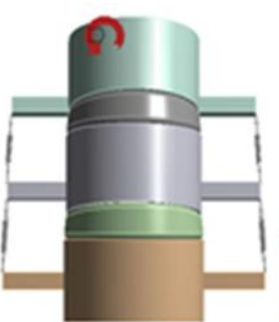

Right Lateral Bending

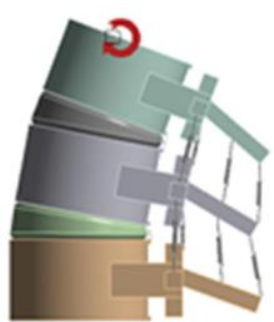

Extension

Figure 2

- L2-L3-L4 Loading and boundary conditions

Table 2 - Simulation 2 results summary

\begin{tabular}{ccccc}
\hline & Flexion & Extension & Left Bending & Right Bending \\
\hline L3 Displacement (mm) & 1.8272 & 1.263 & 2.8389 & 2.8355 \\
\hline $\begin{array}{c}\text { Literature Value (mm) } \\
\text { (Wang, et al., 2006) }\end{array}$ & 1.66 & 0.97 & 3.27 & 3.27 \\
\hline
\end{tabular}

137 Given this data, it can be seen that even with the simpler geometry used within the test rig, 
138 the spine is still undergoing equivalent motion. To ensure the engineering materials used in

139 the test rig are suitable, the materials properties in the simulation were changed to that of

140 ABS and polyurethane foam, as used in the test rig. The data was compared to the model

141 previously described, which used the properties of human tissue so that it could be verified

142 that the materials being used were mechanically equivalent. A close match is seen in Figure

1433 , highlighting how the materials and geometries used within the test rig are a suitable choice.

144 Again, the springs shown represent the tension-only spring elements that model the

145 ligaments.

146 
Spine Simulation (Foam and ABS material)

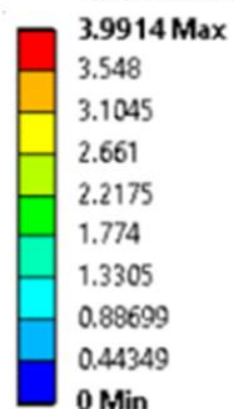

$3.9914 \mathrm{~mm}$ - Flexion
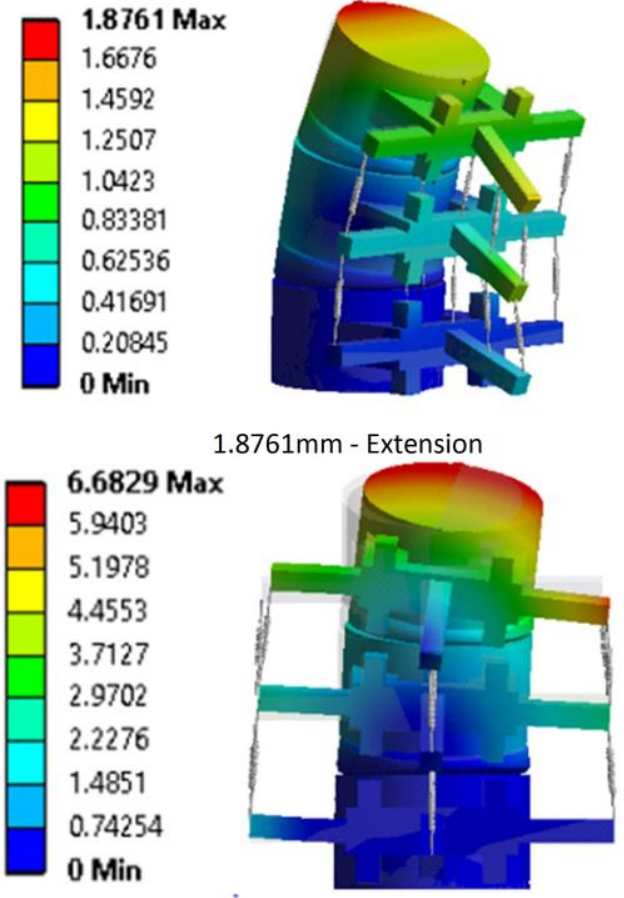

$6.6829 \mathrm{~mm}$ - Right Lateral Bending

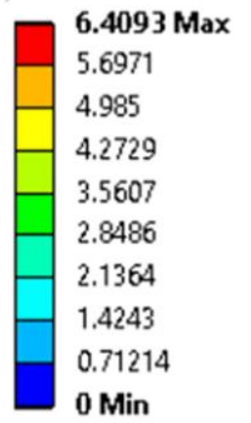

6.4093mm - Left Lateral Bending

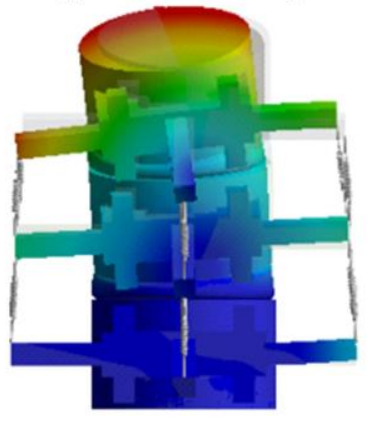

Spine Simulation (Tissue material models used)
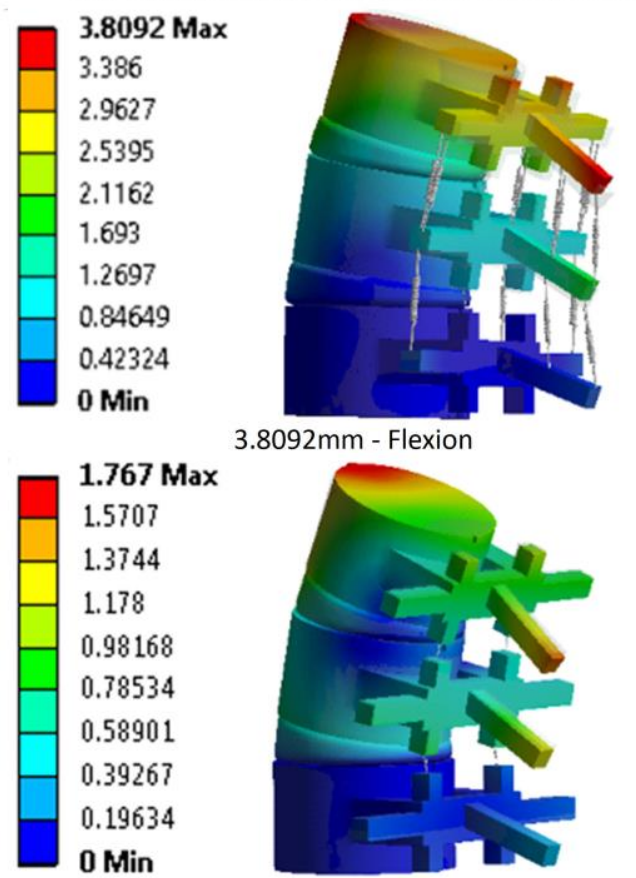

$1.767 \mathrm{~mm}$ - Extension

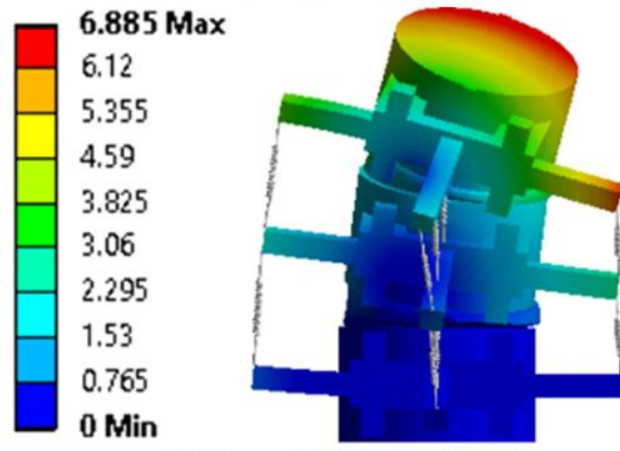

$6.885 \mathrm{~mm}$ - Right Lateral Bending

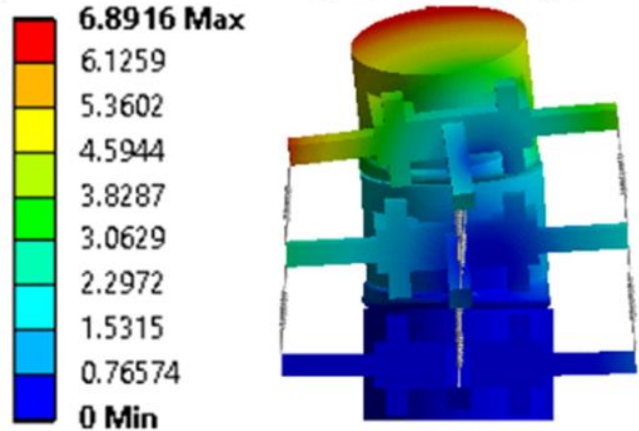

0 Min $6.8916 \mathrm{~mm}$ - Left Lateral Bending

148 Figure 3 - Total L2-L3-L4 displacement comparisons

150 To investigate the mechanical behaviour of the full torso, the spine was added to a torso CAD

151 model. Multiple cross-sectional dimensions were taken from a human torso mannequin to 
152 achieve the required external geometry, as shown in

153
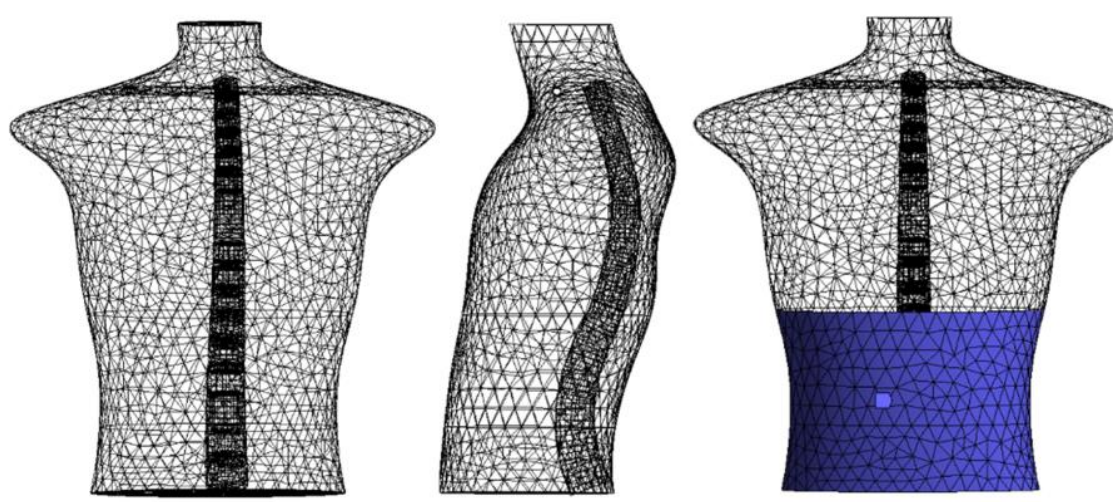

154 Figure 4.

155

156
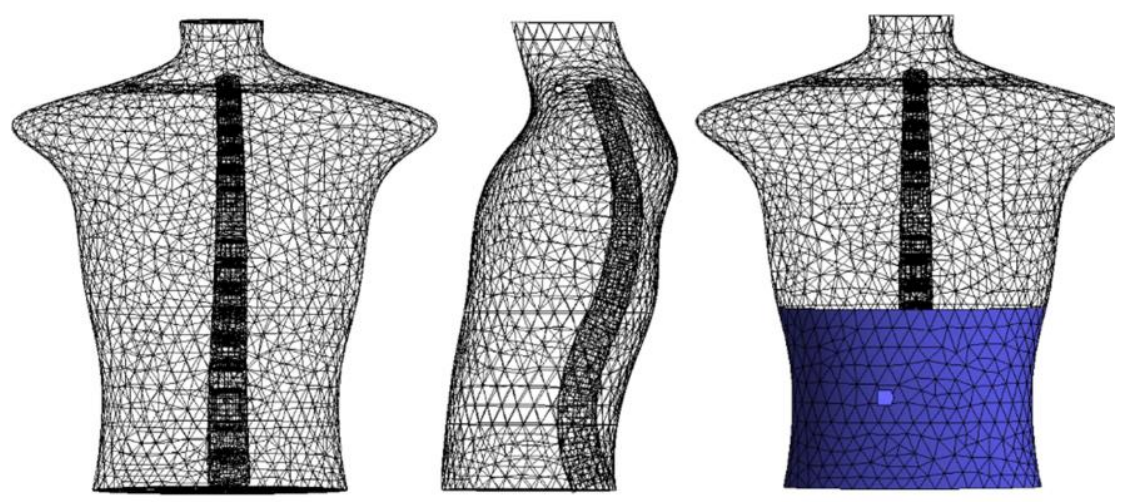

157 Figure 4 - Torso and spine CAD model. The figure on the right shows the position of a

158 hypothetical back brace in blue. This was modelled as an elastic foundation for initial design 159 purposes.

160

161 The final step for verifying the effectiveness of the simulated torso was to show how a simple

162 back brace around the waist achieves a reduction in the range of motion. 

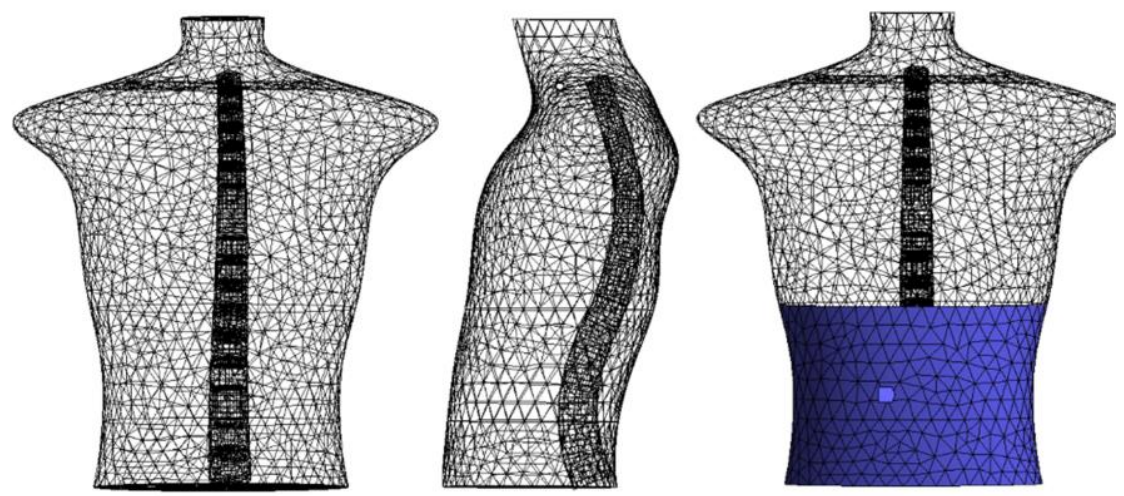

164 Figure 4 shows the sectioned area where a back brace would impart a pressure on the torso.

165 The elastic support boundary condition provides a stiffness normal to the surface it is applied

166 on and is defined through a foundation stiffness. This stiffness is defined as the pressure

167 required to produce a unit of normal deflection (ANSYS, 2017) and thus is representative of

168 an elastic brace being worn.

169 A normal load of $58.4 \mathrm{~N}$ was applied to the sternum, to be consistent with later experiments

170 and to simulate the spine and torso displacement during flexion. Foundation stiffness was

171 incrementally increased and both maximum displacement and lumbar displacement analysed

172 


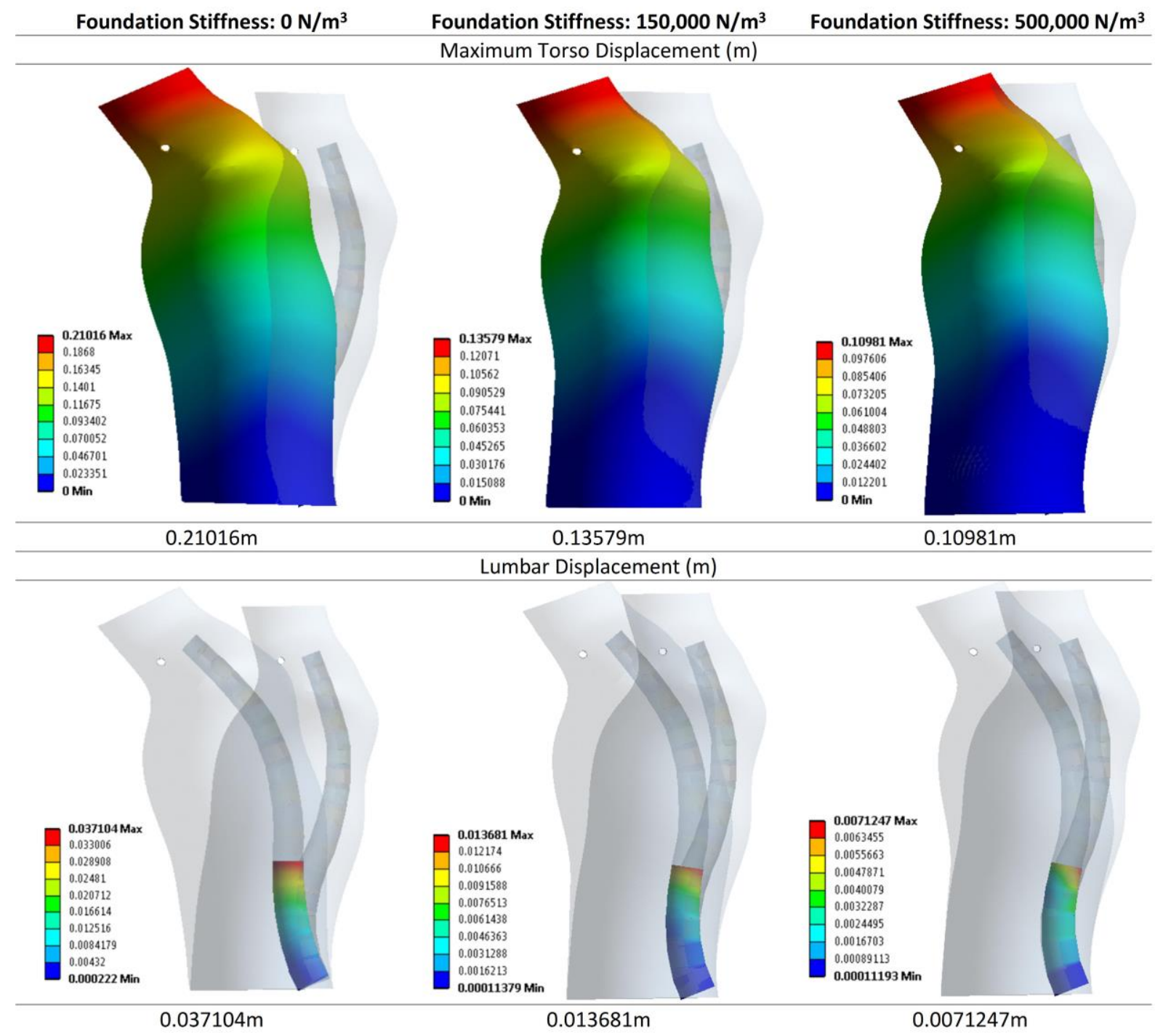

174 Figure 5). It can be seen that through increasing the pressure around the waist, a reduction in

175 the total displacement of the torso is possible. It is also noted that the reduction in

176 displacement is more evident in the lumbar region. It is postulated that data such as that

177 derived from 


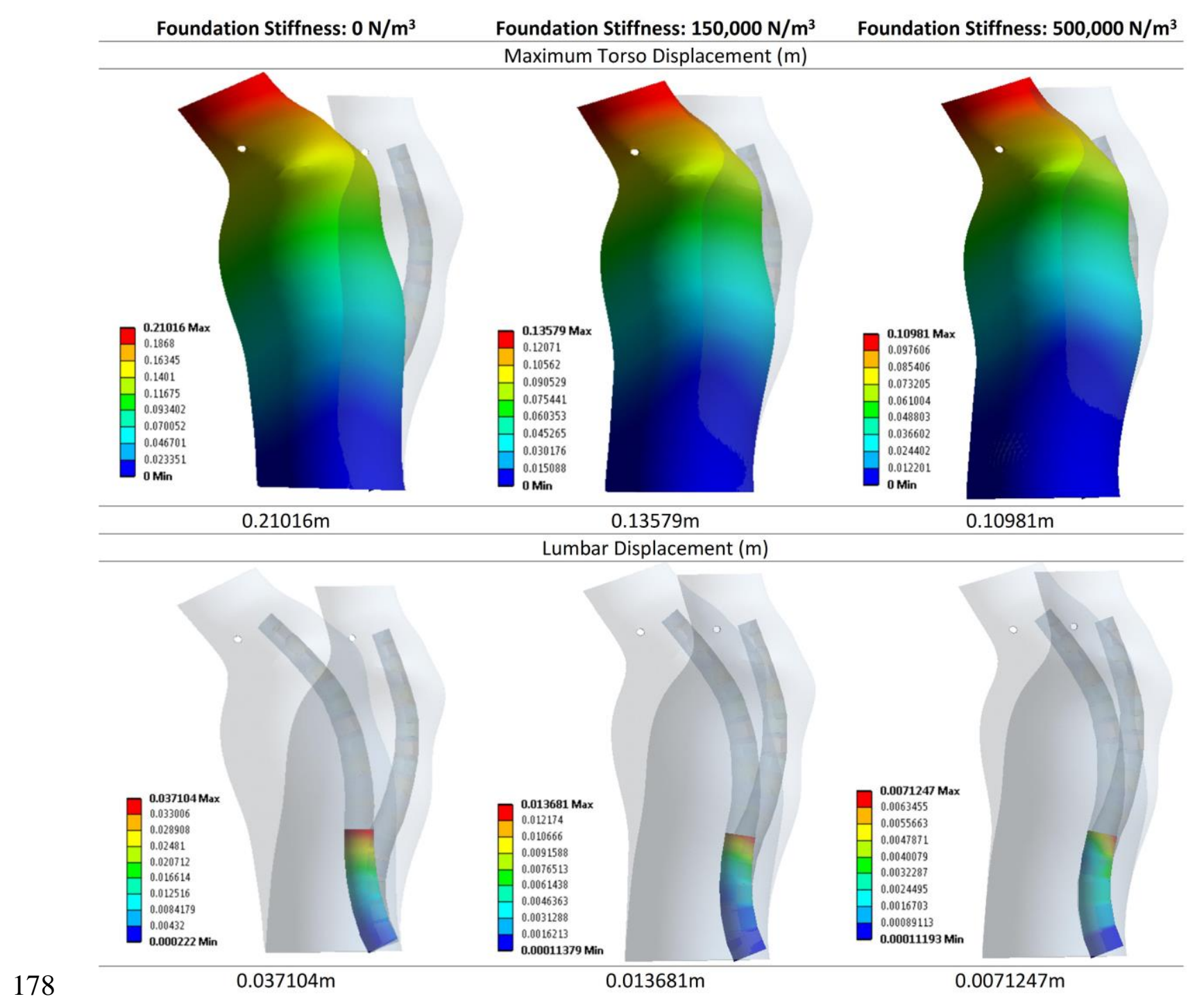

179 Figure 5 may be used to tune or design a back brace to a desired range of motion. 


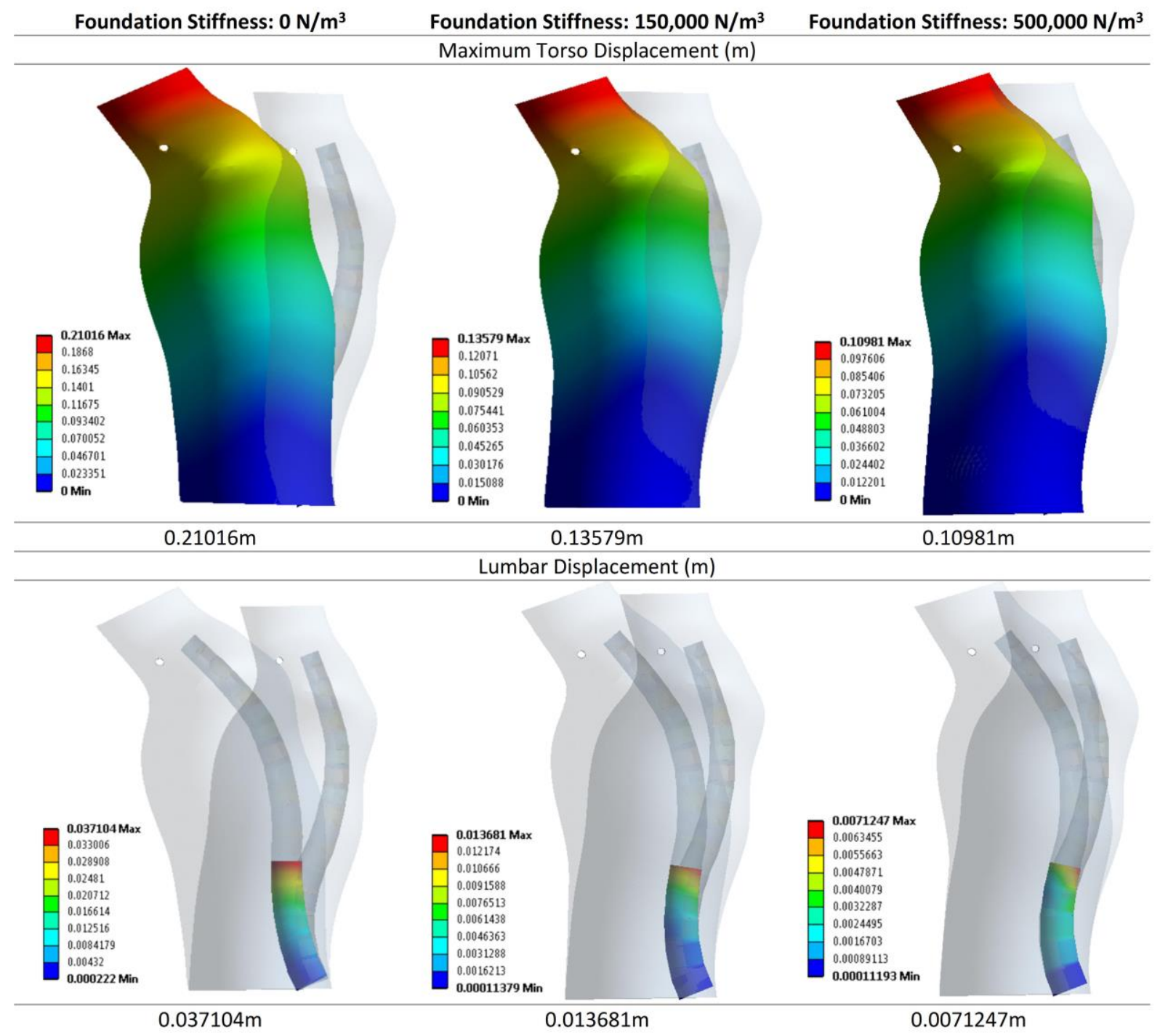

182 Figure 5 - Braced foam torso displacement

\section{Test Rig Fabrication}

185 The test rig comprises two fundamental features: an artificial mechanically equivalent human torso, and a frame mechanism designed to manipulate the torso into flexion, extension, lateral

187 bending and torsional motions. Unlike the FEA models, the fabricated vertebrae were treated

188 as a single material structure to aid in manufacture. This does not affect the mechanical

189 behaviour of the torso. Such a structure lends itself to fused deposition modelling (FDM; an

190 additive manufacturing process), a method well suited to fabricating the unique geometries of

191 vertebrae, and hence the method adopted in this instance. All vertebrae, ribs and sternum 
were additively manufactured using FDM on a Ultimaker 2 (Ultimaker-Geldermalsen,

193 Netherlands) with a $0.4 \mathrm{~mm}$ nozzle. A 3mm diameter ABS1400 feedstock and a nozzle

194 temperature of $240{ }^{\circ} \mathrm{C}$ was used (build plate temperature was $80^{\circ} \mathrm{C}$ ). All intervertebral discs

195 were cast as one collective piece of medium density polyurethane foam (Polycraft 022-

196 medium foam; from MB Fibreglass), in a two-part mould fabricated using FDM. This piece

197 was then cut to the correct geometries in sections using a scalpel.

198 The ribcage contributes to a reduction in flexibility in the torso and an increase in motion

199 stability [27]. The ribcage was designed based on cadaver data of an average male, combined

200 with reverse engineering of existing skeletal models (Panjabi, et al., 1992). Simplifications

201 were made to the geometry of the ribs and sternum to improve the quality of the parts

202 produced using FDM. To further simplify the ribcage design, only essential ribs were

203 included. These include ribs necessary for load distribution. Only four rib pairs were

204 therefore included in the design, connected to vertebrae T1, T3, T5 and T10. The ribcage

205 was also fabricated from ABS1400 to simulate bone within the spinal structure. The

206 assembled CAD model of the artificial spine is shown in

207

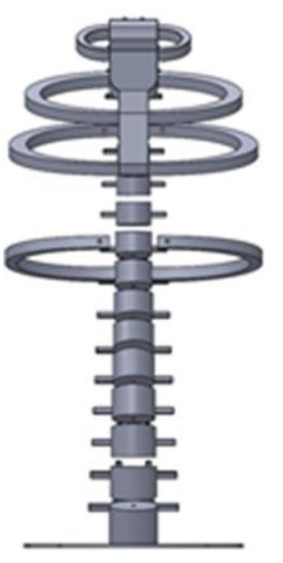

Front
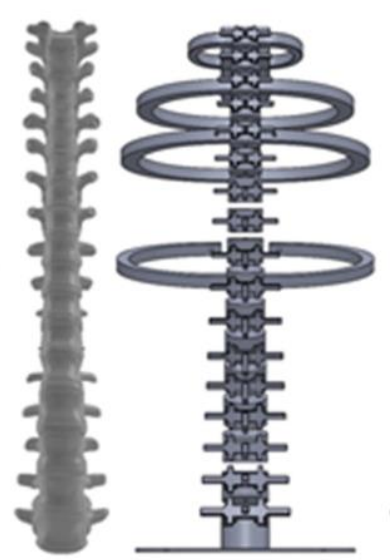

Back

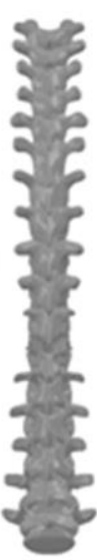

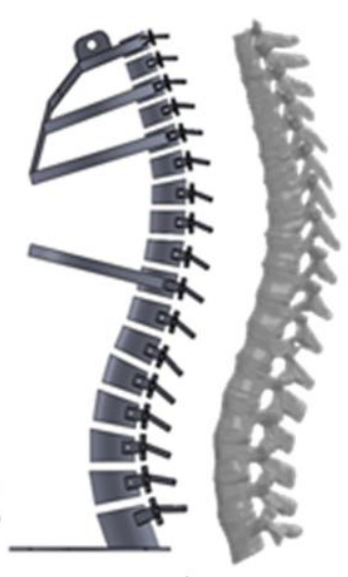

Side

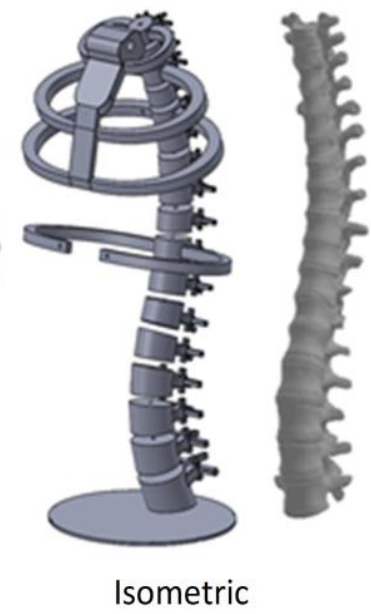

Isometric

208 Figure 6 and compared directly to CT scan data. This CT scan data was retrieved from an open access source (An, 2014) which used Materialise Mimics software (Materialise, 2018) to convert CT slices into a solid model. Radiographic data was taken from a male cadaver 
211 without any apparent spine trauma or pathological effects. The data is used here purely for

212 visual comparison.

213

214

215

216

217 The test rig comprises a steel framework featuring a set of pulley systems capable of

218

219

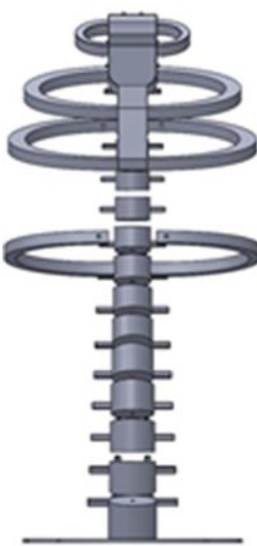

Front

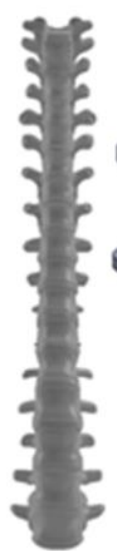

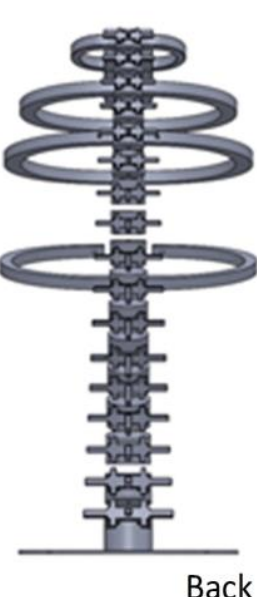

Back
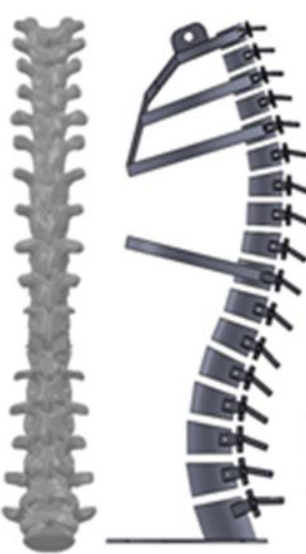

Side

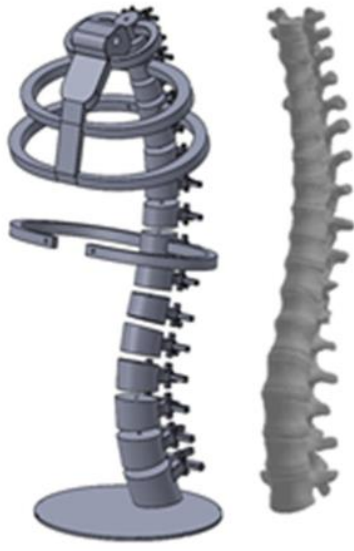

Isometric
Figure 6 - Spine CAD assembly compared with CT scan data of example human spine manipulating the torso (
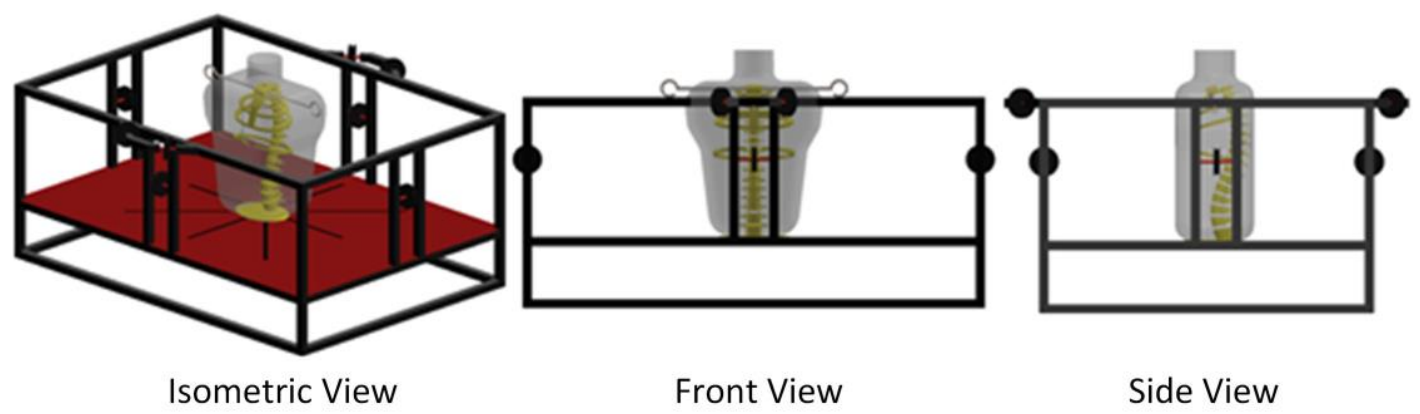

Figure 7). A steel rod connected to the sternum and protruding from the torso acts as the

221 shoulders and provides a connection point for the cables attached to the pulley wheels. The

222 front/back/lateral pulley wheels are lowered in line with the upper abdominals/obliques/lower back in order to generate true anthrompomorphic motion in flexion/extension/lateral bending.

224 Since torsional motion is greatest at the top of the thoracic spine, and progressively less lower 


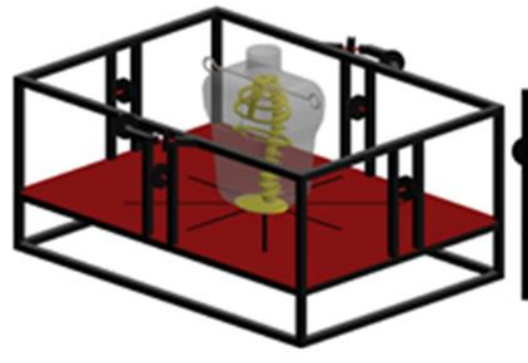

Isometric View

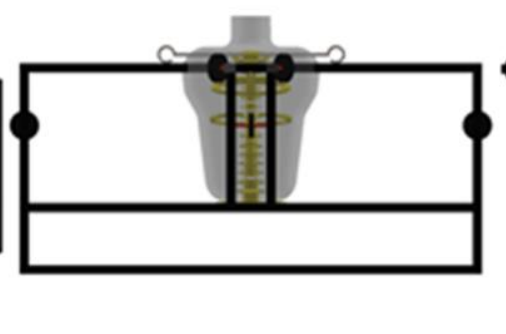

Front View

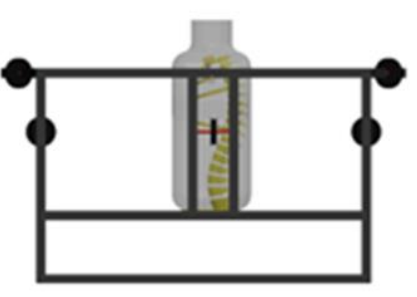

Side View

228 Figure 7 - Test rig CAD assembly

\section{Test Rig Test Method}

The intention of the test rig is to quantify and compare the reduction in motion caused by the presence of various brace designs. Three methods were used to record respective motion displacement: flex sensors attached along the centre of the torso recording bend angle of the torso; image analysis of photographs taken from fixed locations both before and after applying load (see

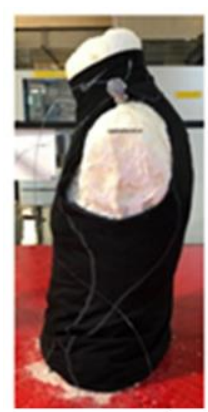

Neutral

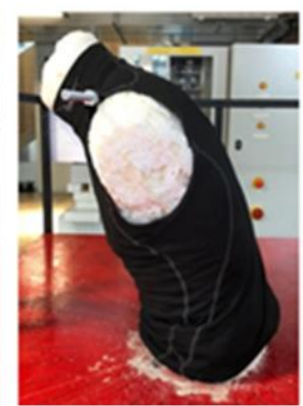

Flexion

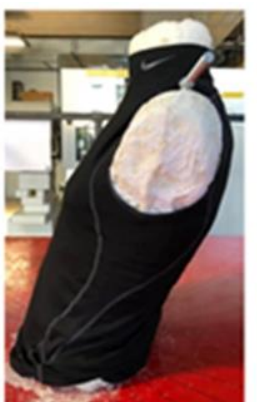

Extension

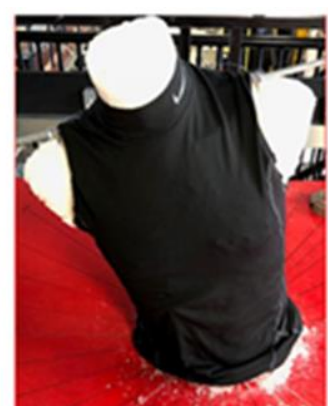

Lateral Bending

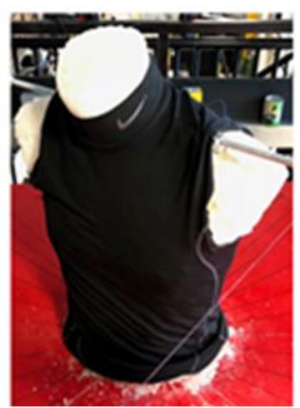

Torsion

Figure 8); and manual measurement of the displacement of a fixed point on the shoulder rod from the horizontal plane.

All three methods were used in recording flexion/extension/lateral bending; however, torsion does not lend itself to use of flex sensors or manual displacement measurement, and hence 
240 relies solely on imaging. A preliminary range of motion test was undertaken on the rig and

241 validated using the FEA (see

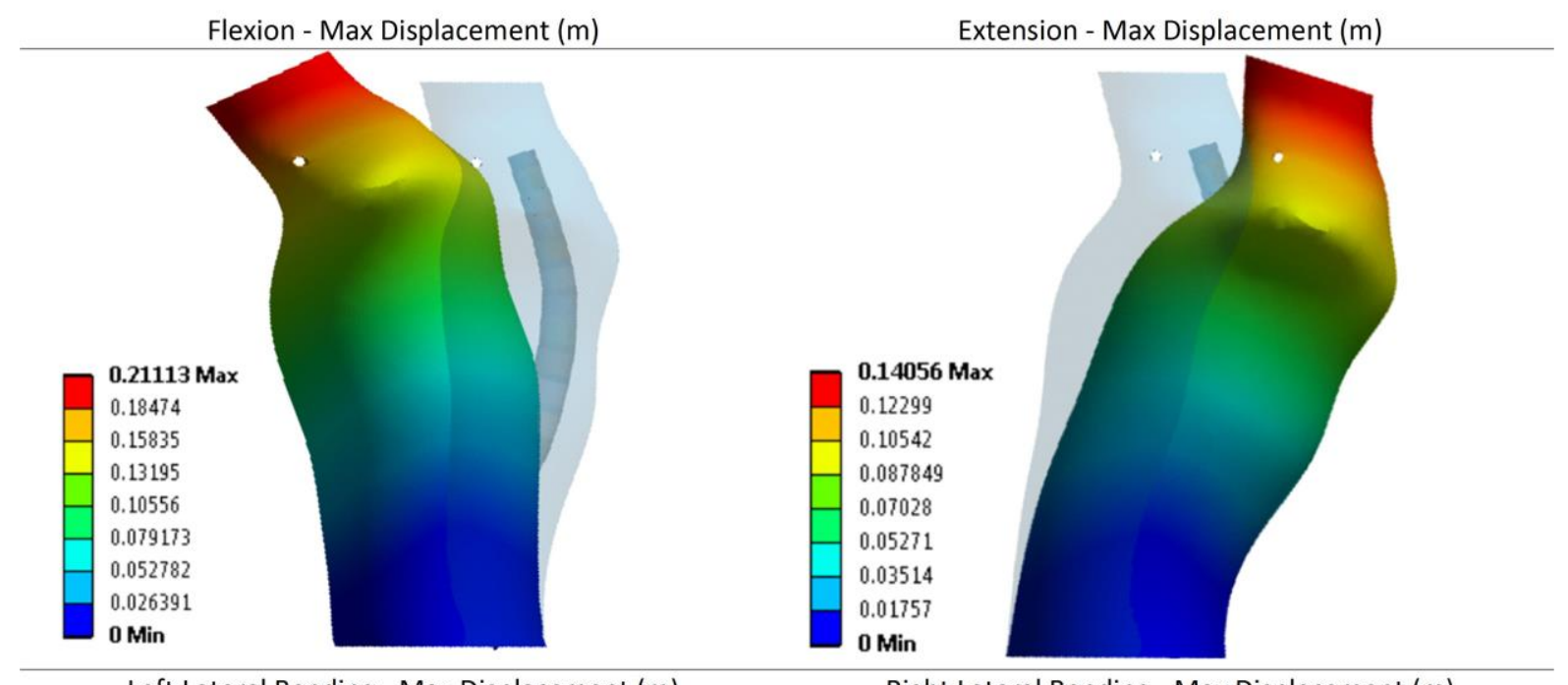

242

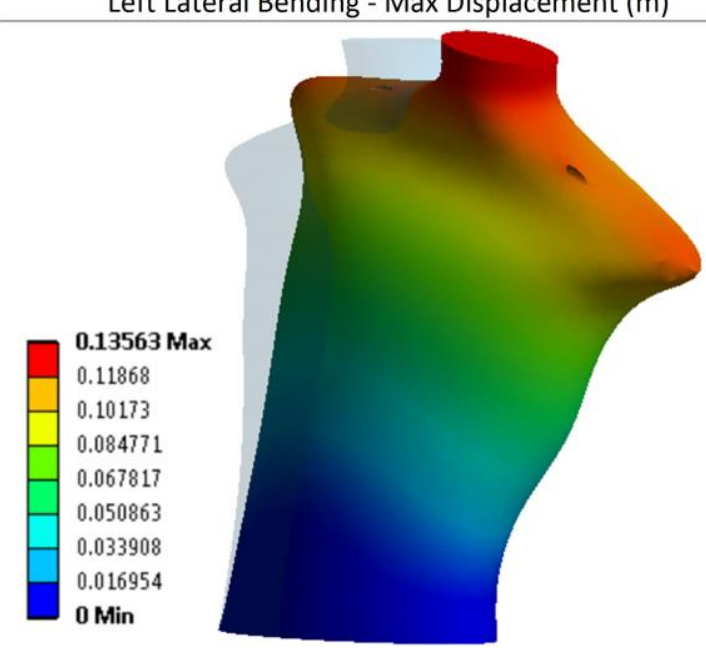

Right Lateral Bending - Max Displacement (m)

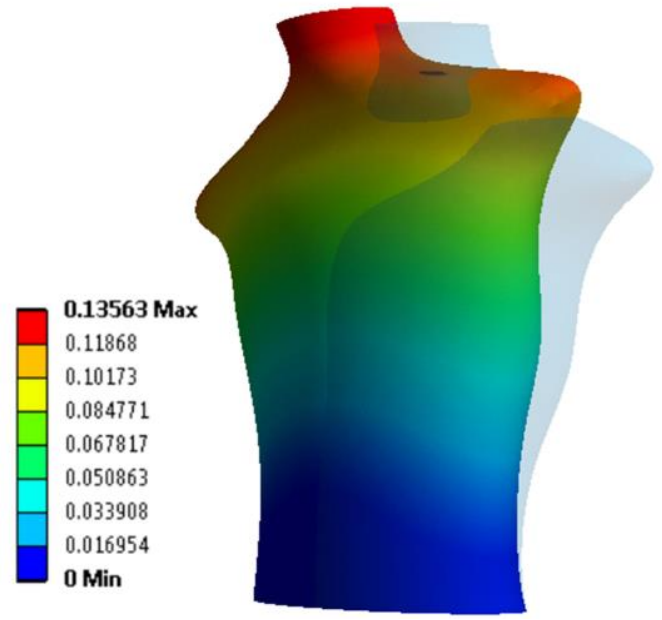

243 Figure 9) model described above, and a summary of the key results obtained is given in Table

244 3. Load was applied to achieve a desired range of motion and the same applied on both the

245 mechanical rig and in simulations to provide the basis for fair comparisons.

246 Table 3 - Test rig range of motion results 


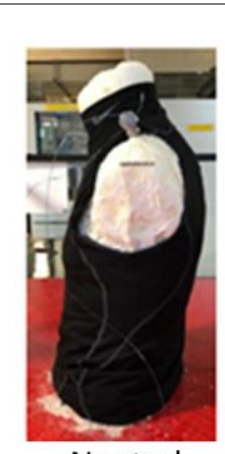

Neutral

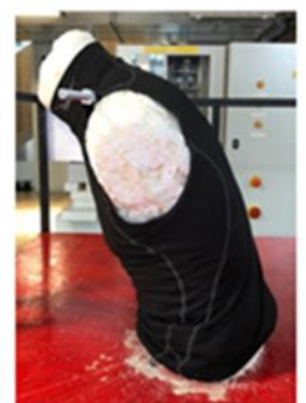

Flexion

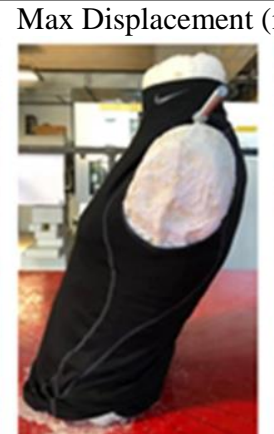

Extension

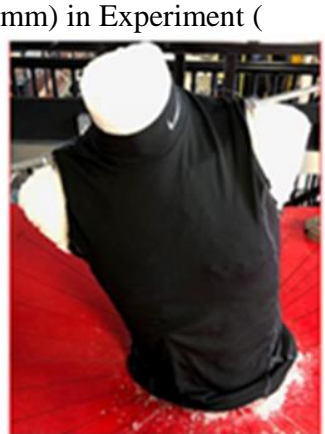

Lateral Bending

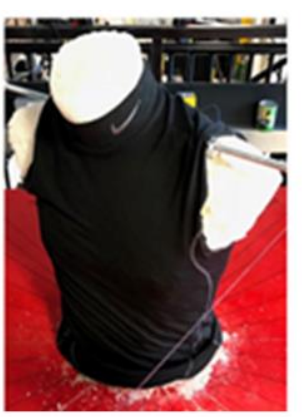

Torsion

Figure 8)

Max Displacement (mm) in Simulation (

$211.1 \quad 14$

Flexion - Max Displacement (m)

Extension - Max Displacement (m)
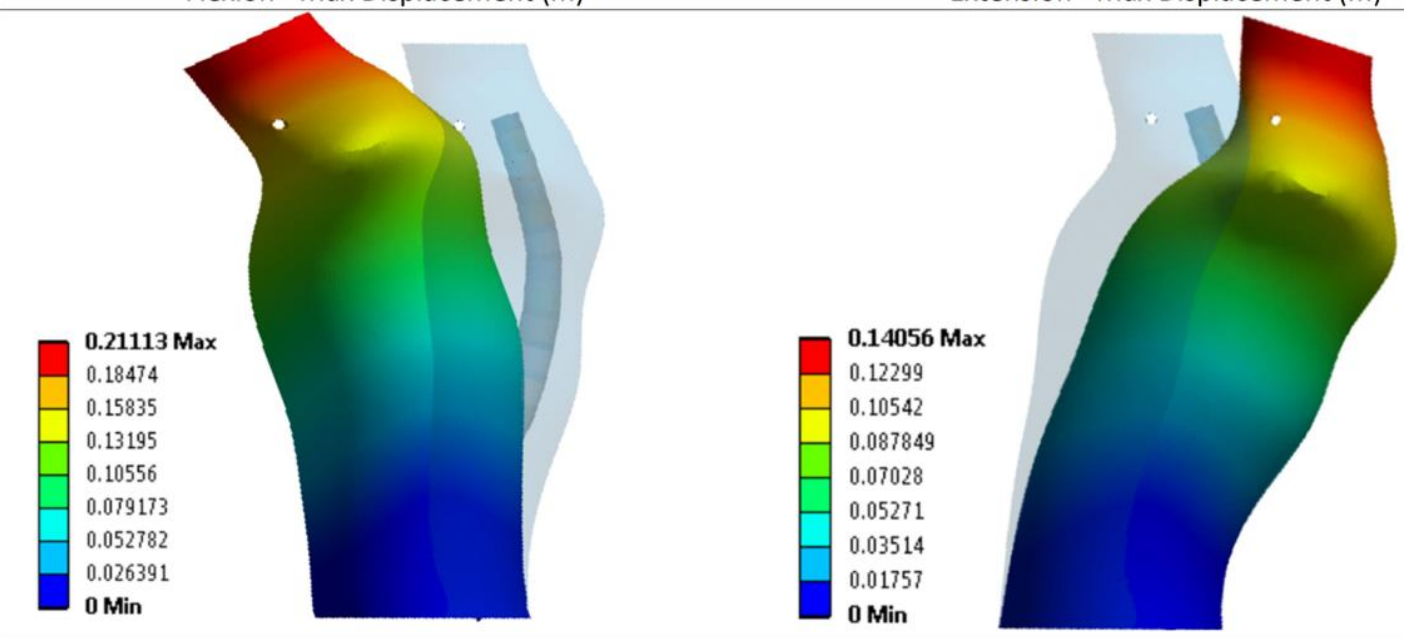

Left Lateral Bending - Max Displacement (m)

Right Lateral Bending - Max Displacement (m)
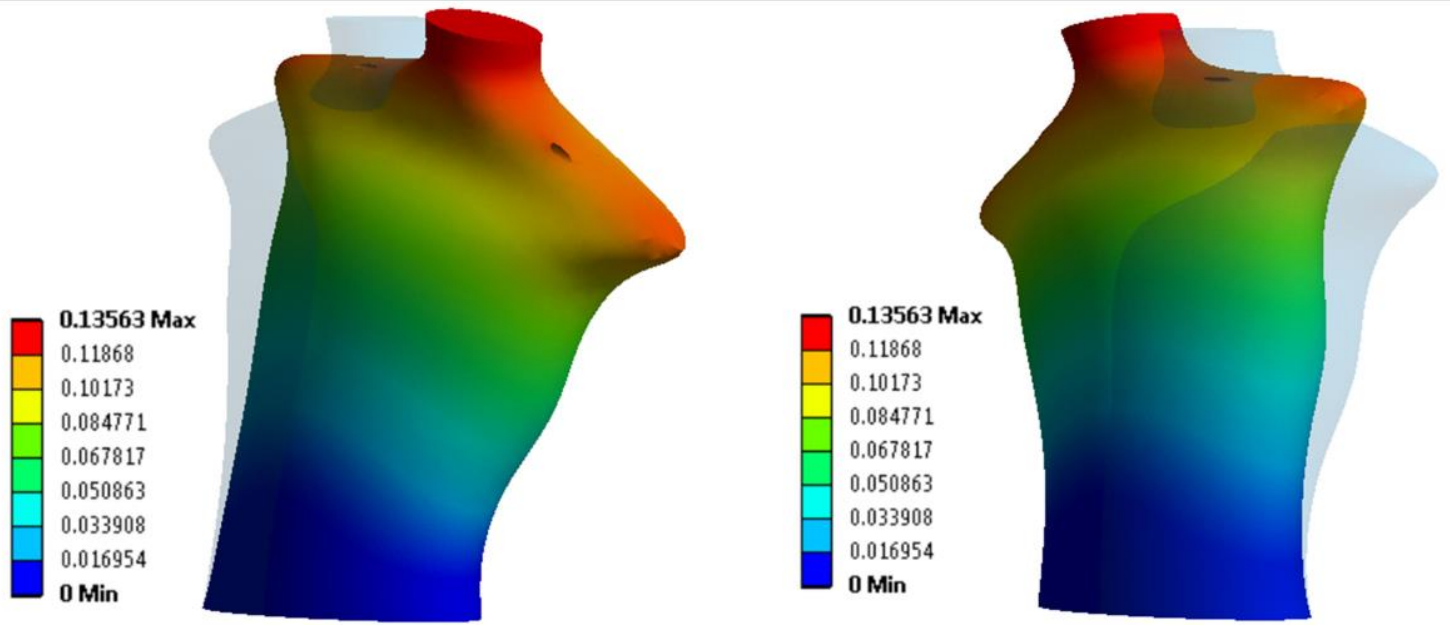

Figure 9) 


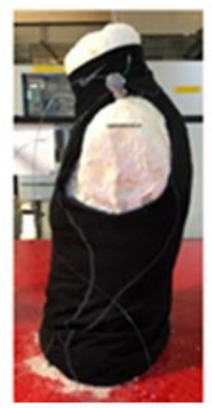

Neutral

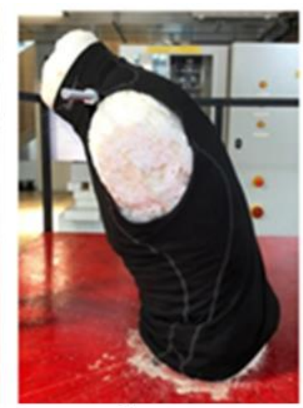

Flexion

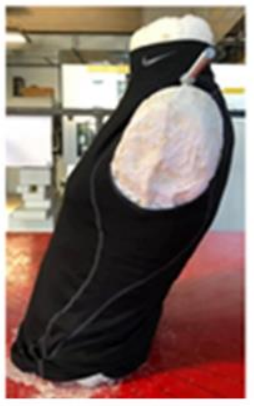

Extension

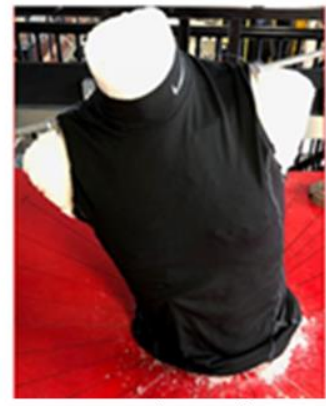

Lateral Bending

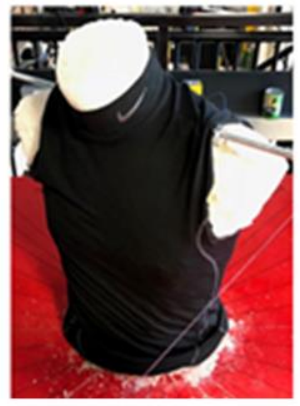

Torsion

249 Figure 8 - Test rig torso motions given loadings stated in Table 3

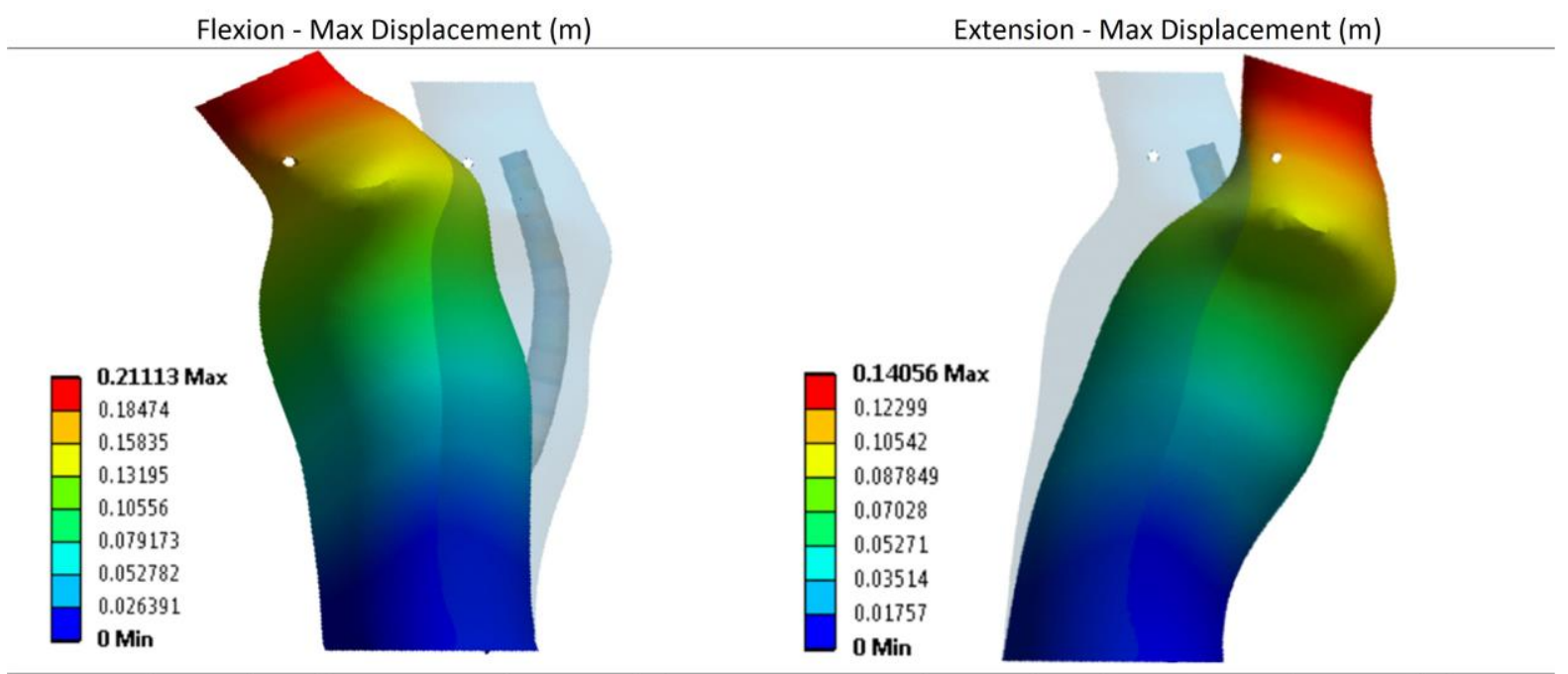

Left Lateral Bending - Max Displacement (m)

Right Lateral Bending - Max Displacement (m)
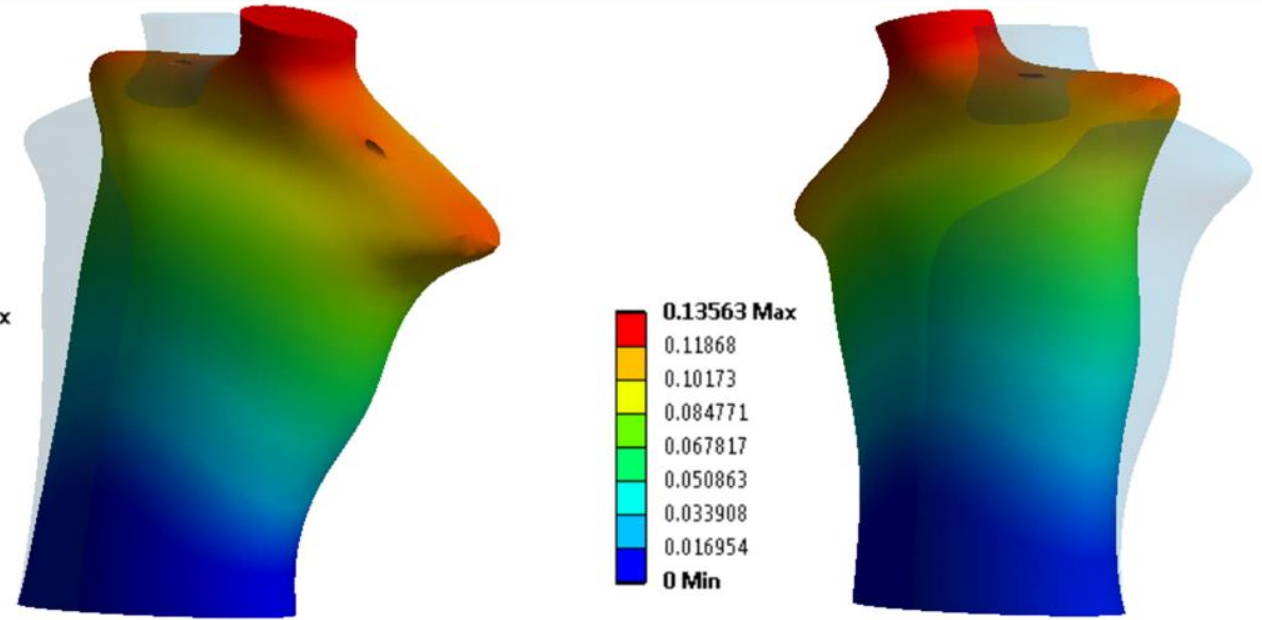

251 Figure 9 - Simulated torso displacements for comparable loadings as test rig shown in 


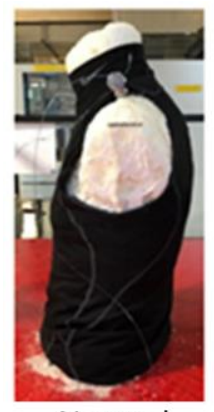

Neutral

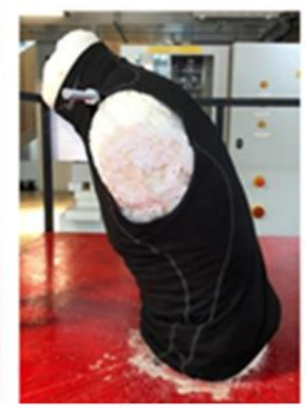

Flexion

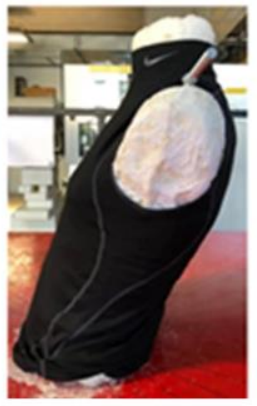

Extension

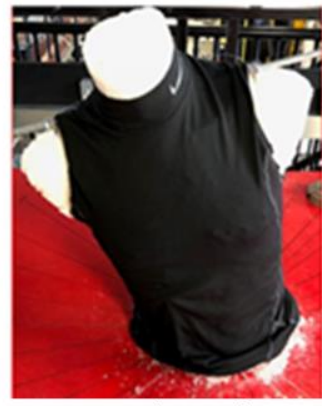

Lateral Bending

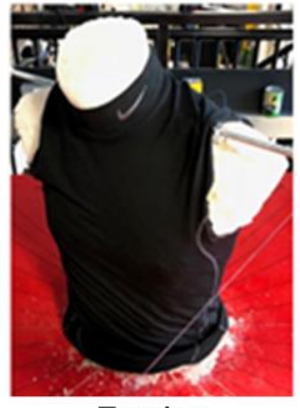

Torsion

253 Figure 8

254 Brace Design

255 The first back brace design utilised a combination of topologically customised shoulder pads

256 and unidirectional chain links
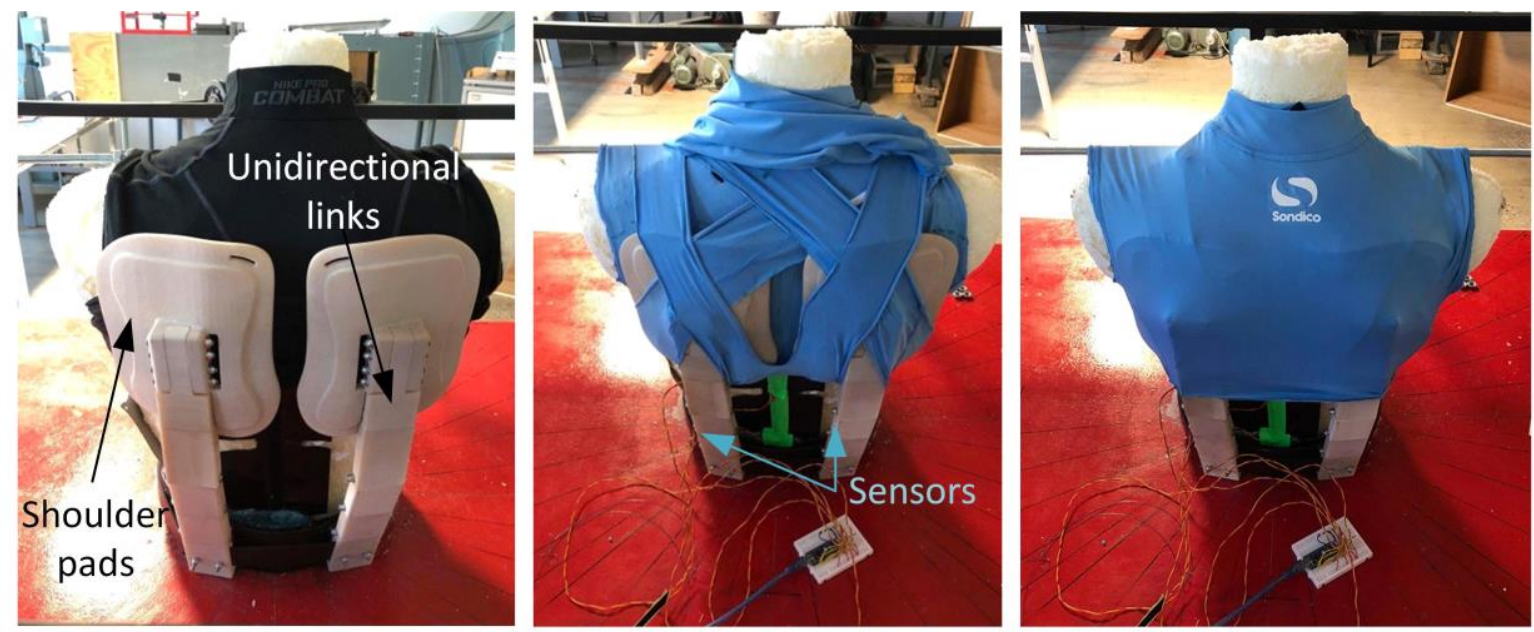

258 Figure 10). The design intent of this concept was to allow flexion while restricting extension,

259 lateral bending and torsion to a noticeable degree. 

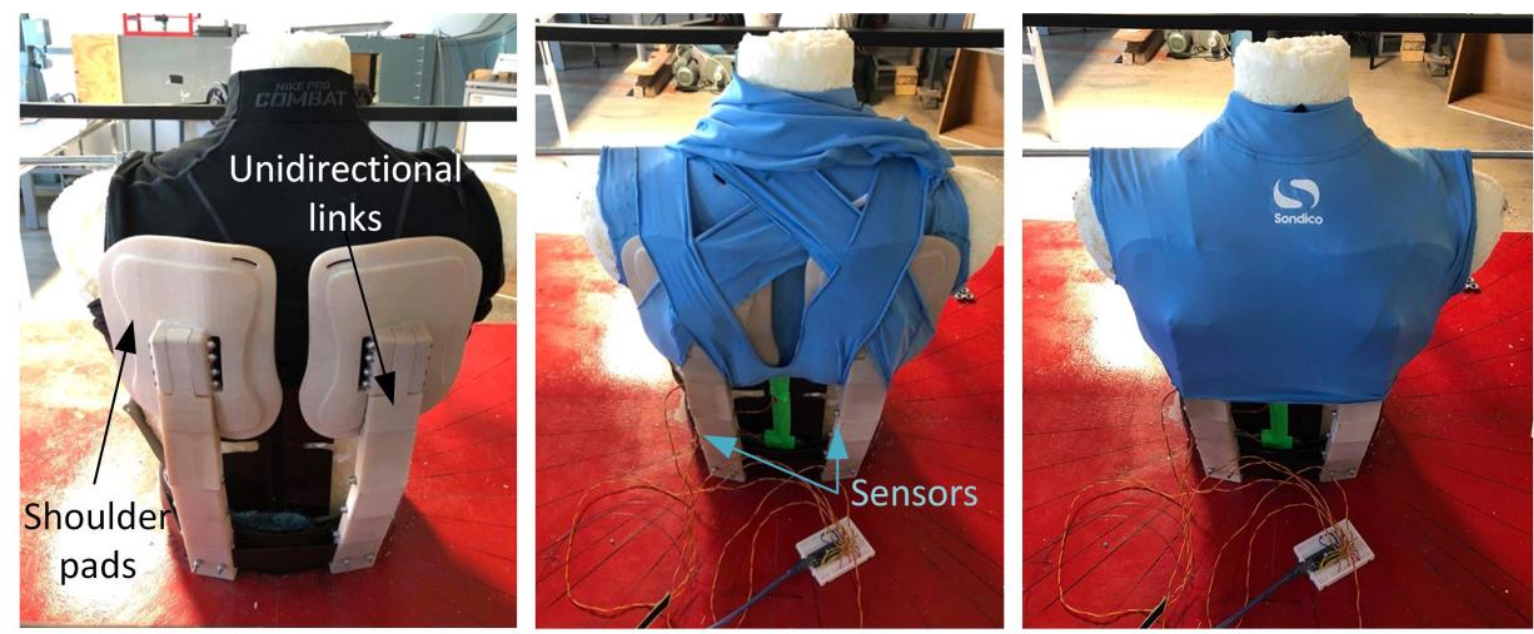

261 Figure 10 - Assembled 'unidirectional' linked back brace at various stages of attachment

263 The second design combined the use of a back plate and rods (

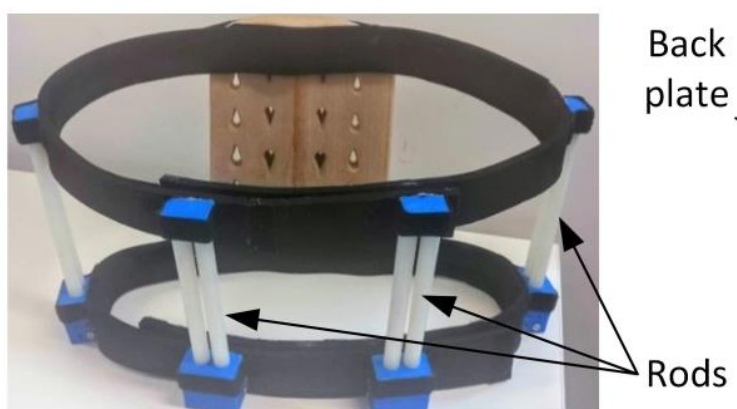

Front View

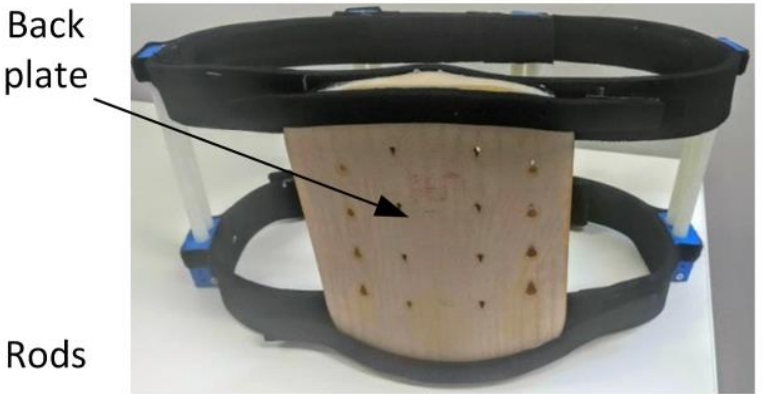

Back View

265 Figure 11). The design intent of this concept was to bridge the gap between the flexible and

266 rigid braces currently available and to restrict flexion, extension and lateral bending in

267 thoracolumbar motion.

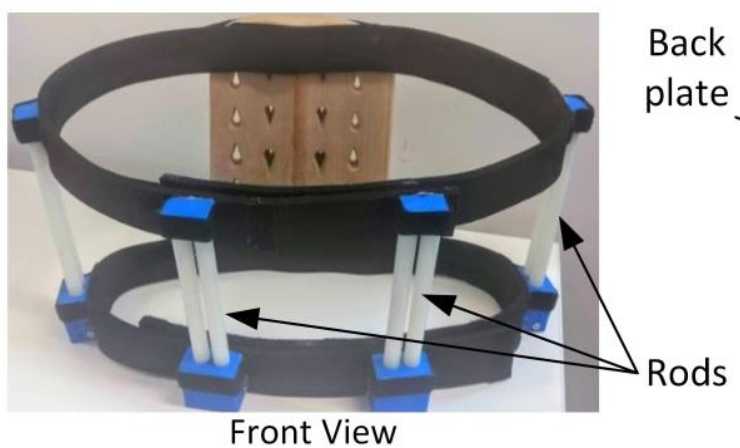

Front View

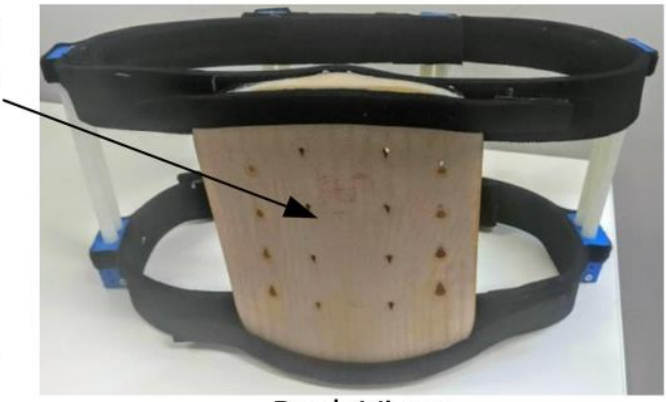

Back View

Figure 11 - Assembled combined plate and rod back brace 
271 The test rig was used to compare the behaviour of the torso when restricted using back braces

272 and to quantifiably compare back brace design. The two novel designs (rodded and linked)

273 were compared to two commercially available back braces, i.e. a leather weightlifting

274 belt (Gold's Gym) and an lumbar support brace, a back belt with metal splints (TONUS

275 0012-01 LUX, Tonus Elast). The four braces tested are shown in

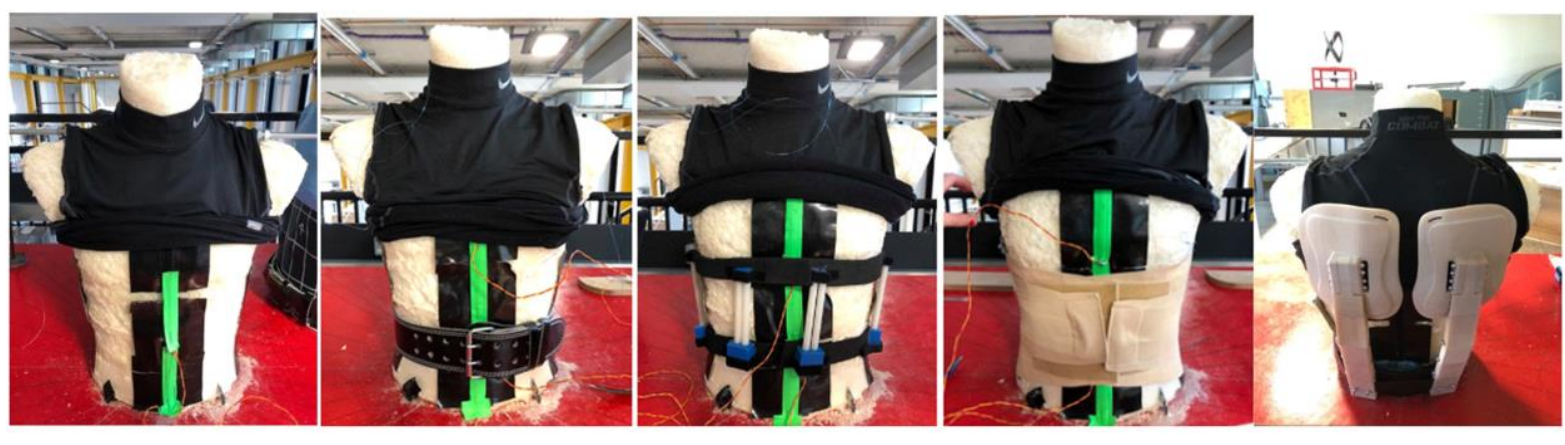

276 No Brace Weightlifting Belt

Rod Brace

Existing Brace

Linked Brace

277 Figure 12, along with the control (no brace).

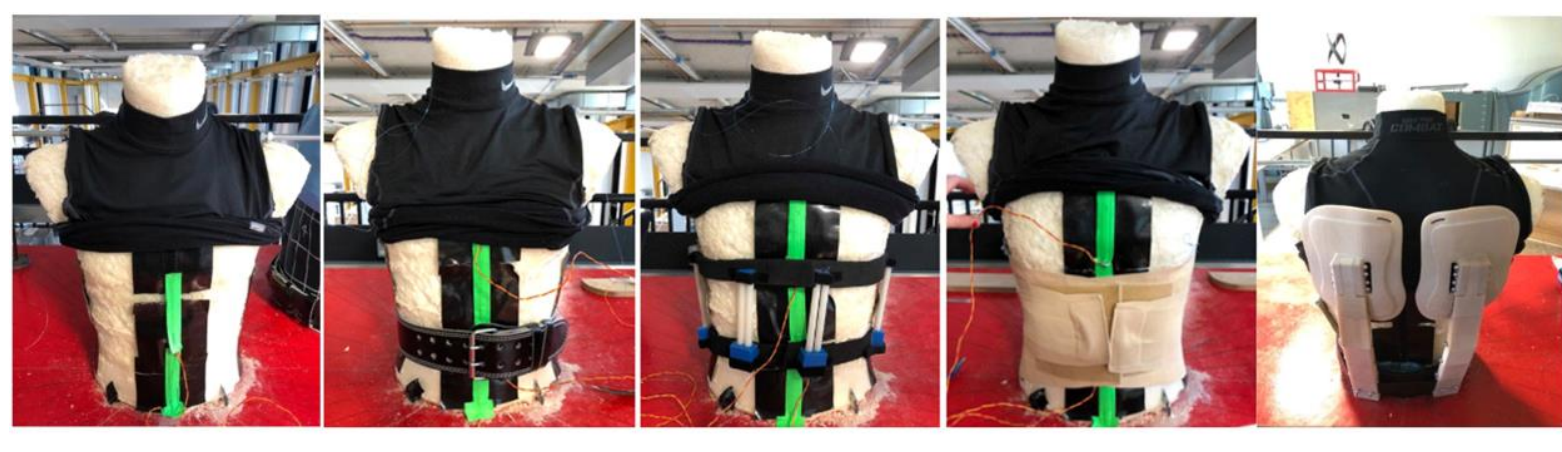
No Brace Weightlifting Belt Rod Brace

279 Figure 12 - Overview of brace conditions tested on the rig 
(a)

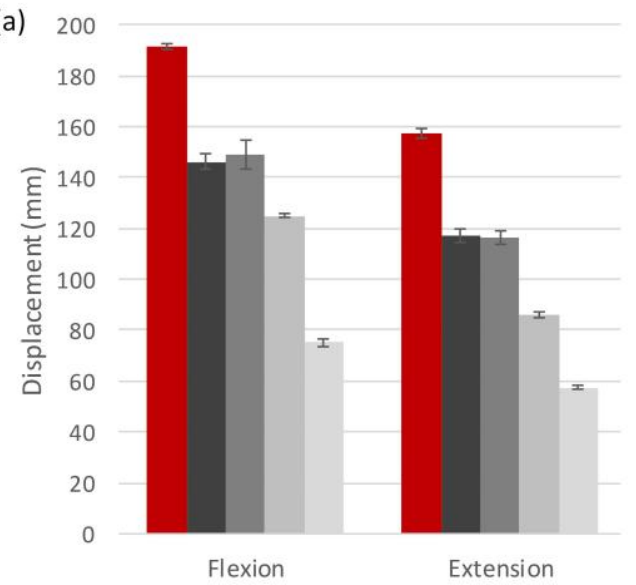

(b) 30

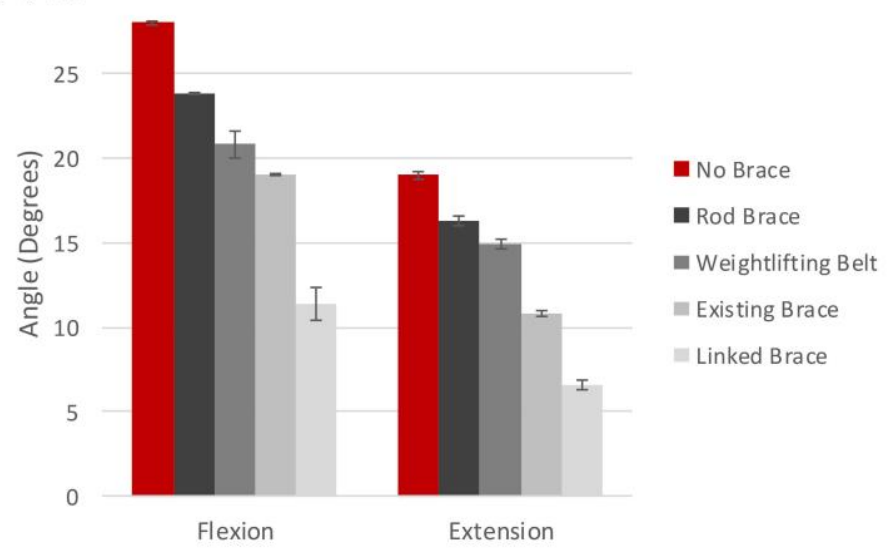

282 Figure 13 shows how in flexion, the linked brace is by far the most restrictive and the rodded

283 brace the least. As expected, the displacement results show a similar pattern to the measured angles. One noticeable difference between the displacement and angle data is the reduction in

285 flexion for the weightlifting belt - the displacement data shows the belt as restricting flexion

286 by less than the rodded brace, whilst the angle data shows more reduction. The difference in

287 final angle between the weightlifting belt and the rodded brace could be indicative of a shift 288 in the centre of rotation.

(a)

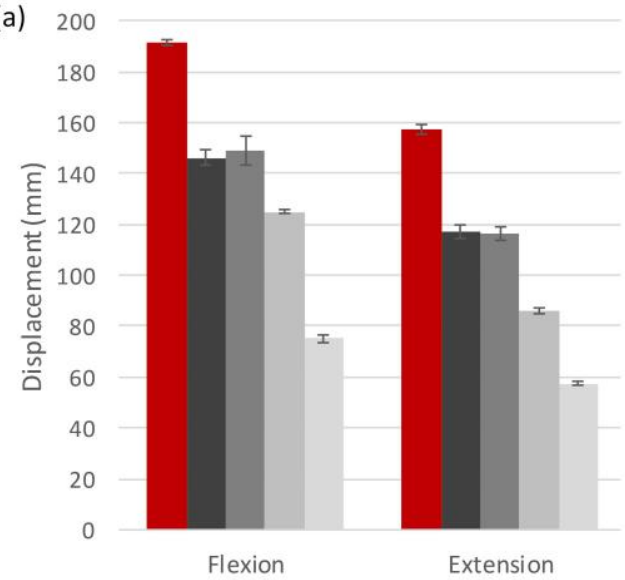

(b) 30

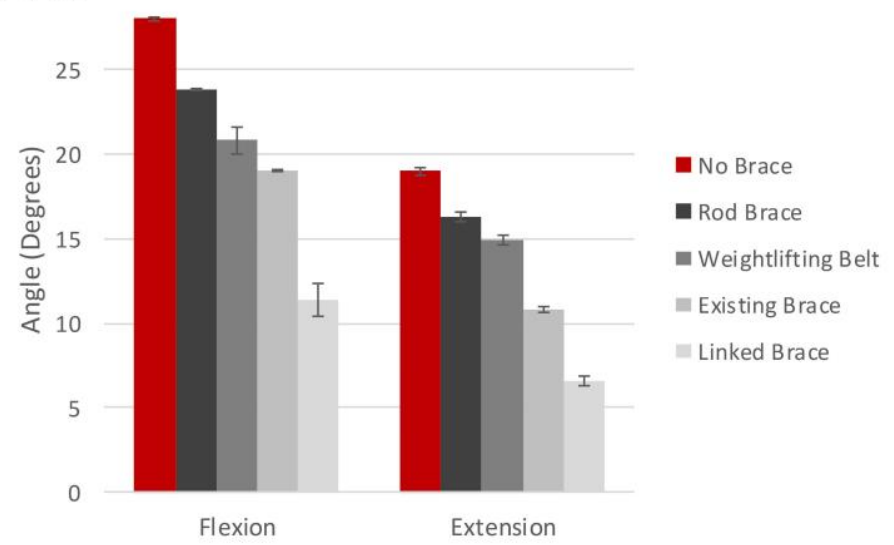

290 Figure 13 - Comparison of brace motion in flexion and extension. (a) Shows maximum

291 deflection, (b) shows angle of tilt 
293 In both cases, lateral bending shows a discrepancy between left and right motion (

(a) 120

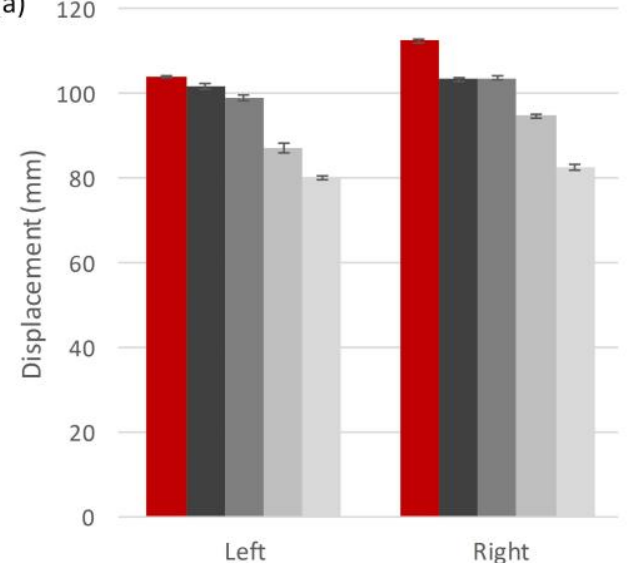

(b) 18

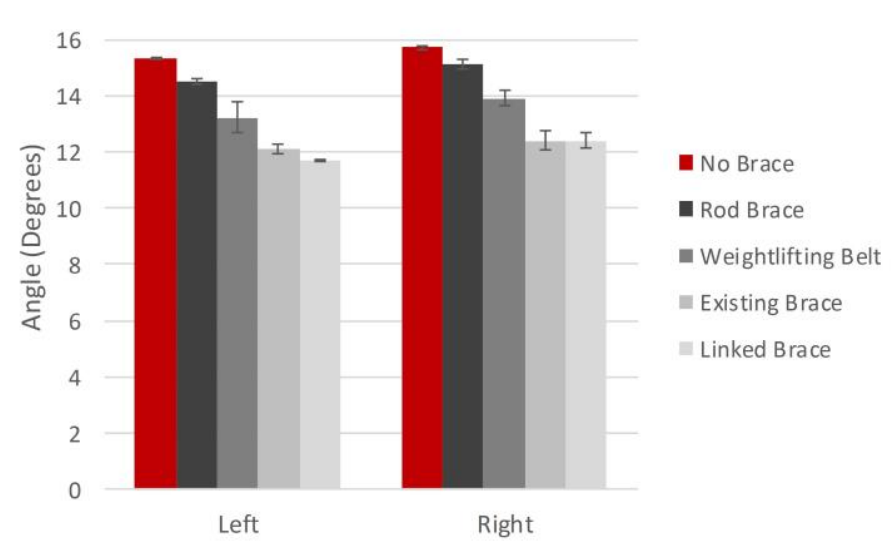

294

Figure 14). This may be due to inhomogeneous properties of the cast foam in the torso. Of

296 the two designed braces, the rod brace can be seen to restrict the least motion and the linked

297 brace the most.

(a) 120

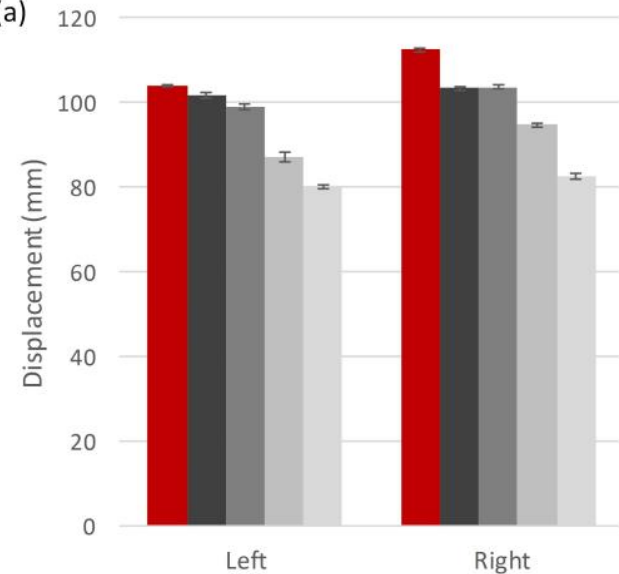

(b) 18

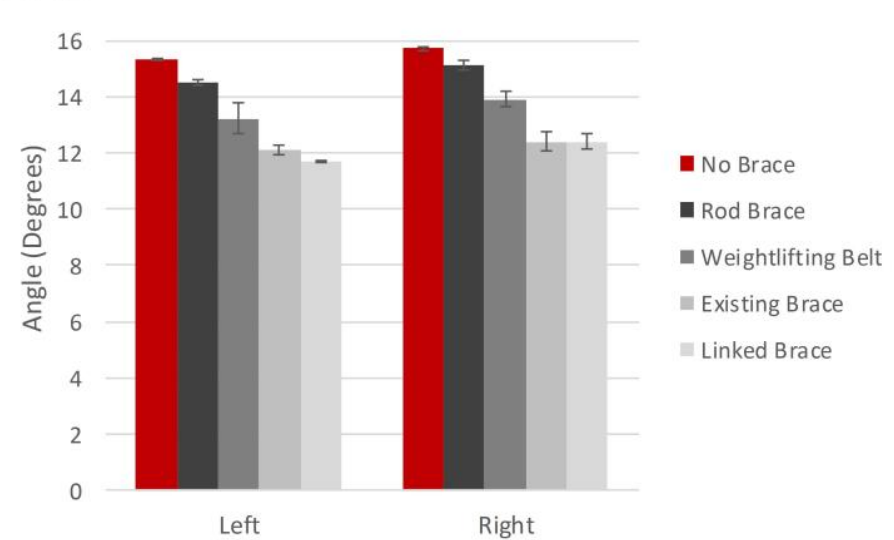

299 Figure 14 - Comparison of brace motion in lateral bending in both left and right directions.

300 (a) Shows maximum deflection, (b) shows angle of tilt

Torsion

302 From the outset of this work, it was suspected that torsion would be the most difficult motion to restrict and this has been shown to be true from the results gained. The two designed

304 braces were less effective at reducing torsion, as evidenced in 


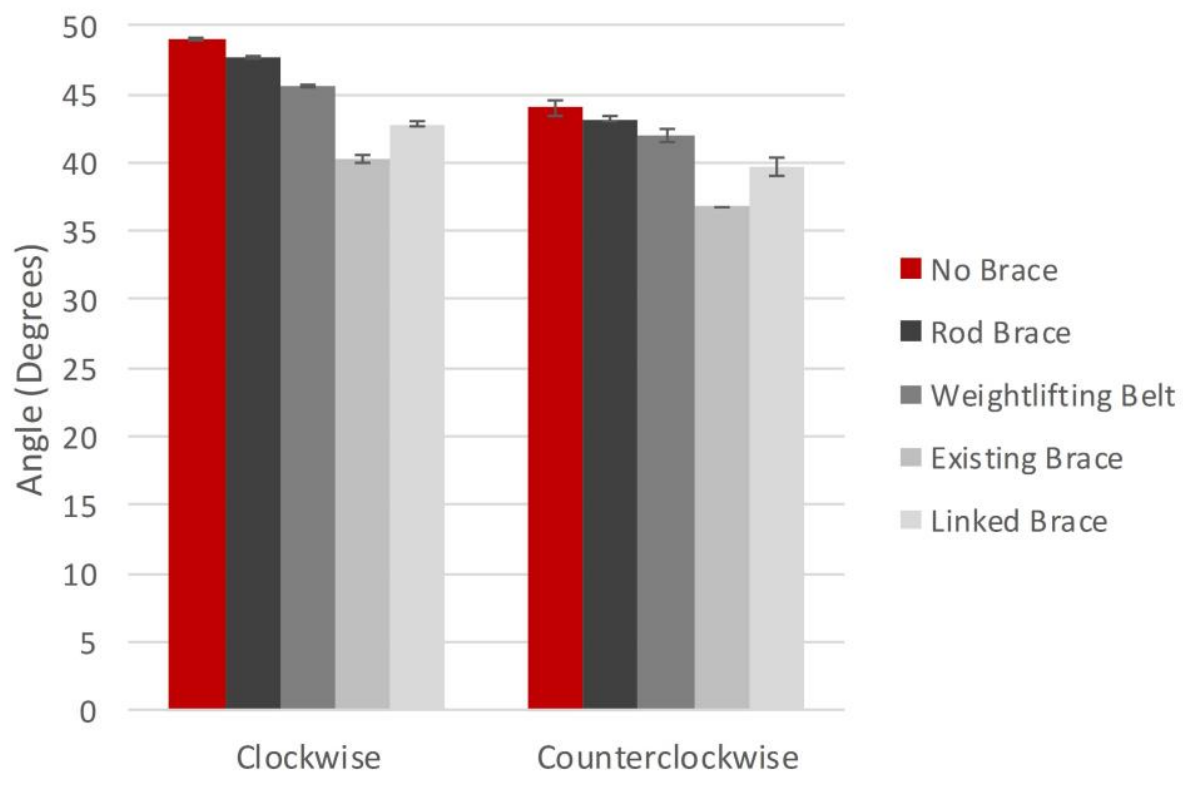

306 Figure 15. The commercial elastic brace is seen to reduce the most motion, likely due to the

307 larger contact area with the body of the torso.

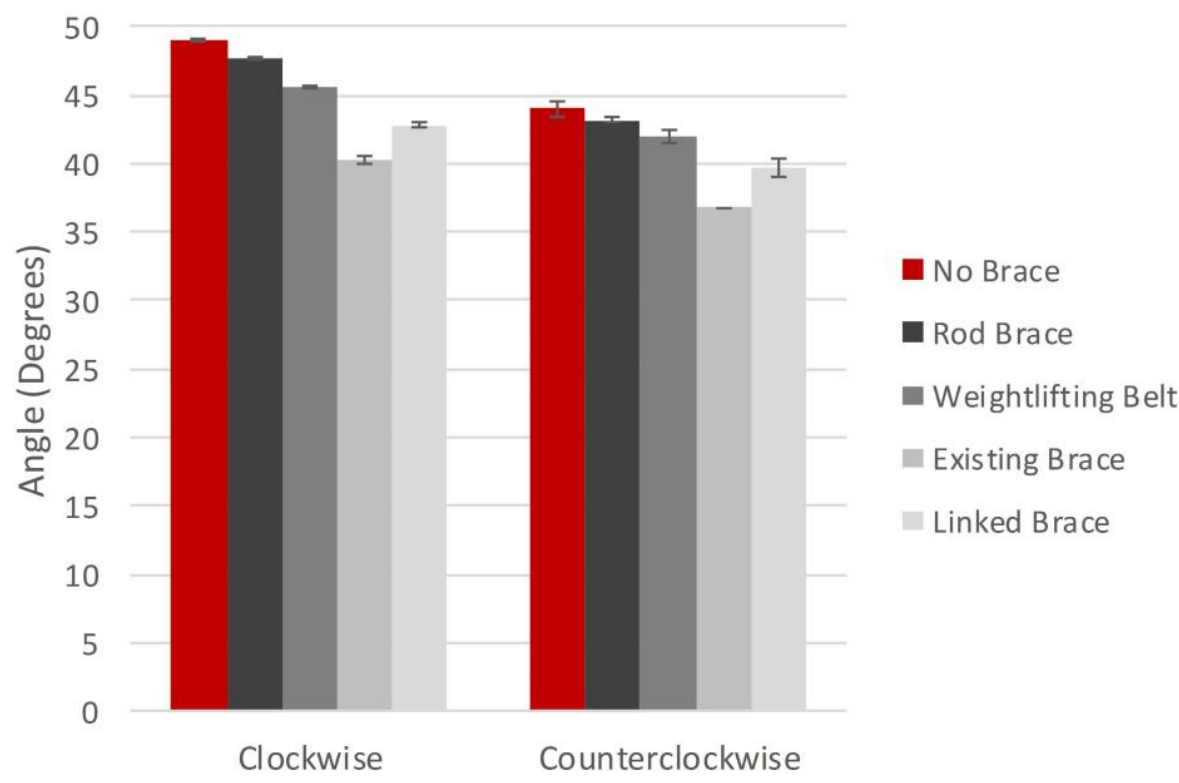

309 Figure 15 - Comparison of angle of rotation of brace in clockwise and anticlockwise torsion

\section{Conclusion}

311 Here an experimental test rig and finite element simulation has been developed for the first

312 time that mimics the mechanical behaviour of the human torso, with the purpose of 
313 facilitating the design of back braces. The test rig and simulation models incorporate a

314 mechanically equivalent artificial spine with geometries and properties that are comparable to

315 those found in human tissues. This allows researchers to test different back brace

316 configurations without having to resort to human testing in the first instance with all the

317 logistical and ethical issues that those tests necessitate. Another advantage of this novel

318 design process is that the back braces can be compared quantifiably in a more convenient

319 manner than in traditional design strategies. It also means that different spine configurations

320 and deformities, such as scoliosis, can be modelled and tested with different back braces

321 without causing any discomfort. It is recognised that ultimately, testing on humans is

322 necessary in order to optimise for factors such as comfort and muscle engagement, but this

323 new design process should facilitate innovation in this field.

\section{Acknowledgments}

325 Competing interests: None declared

326 Funding: Lancaster University Engineering Department

327 Ethical approval: Not required

$328 \quad$ References

329 An, N., 2014. Human spine. [Online]

330 Available at: https://grabcad.com/library/human-spine-1

$331 \quad$ [Accessed 01 October 2018].

332 ANSYS, 2017. Workbench - Mechanical Introduction 18.0.

333 Bayoglu, R. et al., 2019. Twente Spine Model: A thorough investigation of the spinal loads in

334 a complete and coherent musculoskeletal model of the human spine. Medical engineering \& 335 physics, Volume 68, pp. 35-45. 
336 Bonnaire, R. et al., 2014. Biomechanical analysis and modelling of lumbar belt: parametric study. Computer Methods in Biomechanics and Biomedical Engineering, S1(62-63), p. 17. element model of the lumbar spine, s.l.: Master Graduation Thesis, Scuola di Ingegneria

340 Industriale e dell'Informazione Corso di Laurea Magistrale in Ingegneria Biomedica.

341 Cholewicki, J., McGill, K., Shah, K. R. \& Lee, A. S., 2010. The effects of a three-week use

342 of lumbosacral orthoses on trunk muscle activity and on the muscular response to trunk

343 perturbations. BMC Musculoskeletal Disorders, Volume 11.

344 Cholewicki, J., McGill, S. M. \& Norman, R. W., 1995. Comparison of muscle forces and 345 joint load from an optimization and EMG assisted lumbar spine model: Towards

346 development of a hybrid approach. Journal of Biomechanics, 28(3), pp. 321-331.

347 Cholewicki, J., Reeves, N. P., Everding, V. Q. \& Morrisette, D. C., 2007. Lumbosacral 348 orthoses reduce trung muscle activity in a postural control task. Journal of Biomechanics, 40(8), pp. $1731-1736$.

350 Dreischarf, M. et al., 2014. Comparison of eight published static finite element models of the intact lumbar spine: predictive power of models improves when combined together. Journal of Biomechanics, 47(8), pp. 1757-1766.

Eisinger, D. B., Kumar, R. \& Woodrow, R., 1996. Effect of lumbar orthotics on trunk muscle strength. American Journal of Physical Medicine and Rehabilitation, 75(3), pp. 194-197. Fayolle-Minon, I. \& Calmels, P., 2008. Effect of wearing a lumbar orthosis on trunk muscles: Study of the muscle strength after 21 days of use on healthy subjects. Joint Bone Spine, 357 75(1), pp. 58-63.

358 Gómez, F., Lorza, R., Bobadilla, M. \& García, R., 2017. Improving the process of adjusting the parameters of finite element models of healthy human intervertebral discs by the multi-

360 response surface method. Materials, 10(10), pp. 1116-1154. 
Available at: https://www.spineuniverse.com/treatments/bracing/back-conditions-treatedspinal-bracing

364 Hoy, D. et al., 2014. The global burden of low back pain: estimates from the Global Burden 365 of Disease 2010 study. Annals of the Rheumatic Diseases, 73(6), pp. 968-974.

366 Hsu, J. D., Michael, J. \& Fisk, J., 2008. AAOS Atlas of orthoses and assistive devices e-book. 367 s.l.:Elsiever Health Sciences.

368 Huynh, K. T., Gibson, I. \& Gao, Z., 2012. Development of a Detailed Human Spine Model 369 with Haptic Interface. In Haptics Rendering and Applications. InTech, pp. 165-194.

370 Ivancic, P. C., Cholewicki, J. \& Radebold, A., 2002. Effects of the abdominal belt on musclegenerated spinal stability and L4/L5 joint compression force. Ergonomics, 45(7), pp. 501513.

373 Kawaguchi, Y., Gejo, R., Kanamori, M. \& Kimura, T., 2002. Quantitative analysis of the

374 effect of lumbar orthosis on trunk muscle strength and mussle activity in normal subjects.

375 Journal of Orthopaedic Science, Volume 7, pp. 483-489.

376 Kurutz, M., 2010. Finite element modelling of human lumbar spine. Finite Element Analysis.

$377 \quad$ InTech.

378 Lariviere, C., Caron, J.-M., Preuss, R. \& Mecheri, H., 2014. The effect of different lumbar

379 belt designs on lumbopelvic rhythm in healthy subjects. BMC Musculoskeletal Disorders, 380 15(307).

381 Longo, U. G. et al., 2012. Conservative management of patients with an osteoporotic 382 vertebral fracture: a review of the literature.. The Journal of Bone and Joint Surgery, 94(2), pp. $152-157$. 
Available at: https://www.materialise.com/en/medical/software/mimics

Morl, F. \& Bradl, I., 2013. Lumbar posture and muscular activity while sitting during office work. Journal of electromyography and kinesiology, 23(2), pp. 362-368.

Office for National Statistics, 2017. Work-related Musculoskeletal Disorders (WRMSDs)

Statistics in Great Britain 2017, London: Office for National Statistics.

Panjabi, M. et al., 1992. Human lumbar vertebrae. Quantitative three-dimensional anatomy. Spine, 17(3), pp. 299-306.

Pitzer, M. et al., 2016. A numerical study to determine the effectof ligament stiffness on kinematics of thelumbar spine during flexion. BMC Musculoskeletal Disorders, 17(95). Rohlmann, A. et al., 2006. Determination of trunk muscle forces for flexion and extension by using a validated finite element model of the lumbar spine and measured in vivo data. Journal of Biomechanics, 39(6), pp. 981-989.

Schmidt, H. et al., 2006. Application of a new calibration method for a three-dimensional

399 finite element model of a human lumbar annulus fibrosus. Clinical Biomechanics, 21(4), pp. $400 \quad 337-344$.

401 Seo, K., Cho, C. \& Hong, S., 2013. Evaluation of the shock absorption properties of rigid 402 polyurethane and polystyrene foam used in a small transport package. Packaging, Transport, 403 Storage \& Security of Radioactive Material, 16(2), pp. 145-150.

404 Swamy, A., 2014. Material selection for modeling of intervertebral disc. Int J Scientific

405 Engineering and Research, 2(4), pp. 51-53.

406 Ultimaker, 2017. Technical data sheet ABS. [Online]

407 Available at: http://www.farnell.com/datasheets/2310520.pdf 
408 Wagnac, E. et al., 2011. Calibration of hyperelastic material properties of the human lumbar 409 intervertebral disc under fast dynamic compressive loads. J Biomech Eng., 133(10), p.

410101007.

411 Wang, J. P. et al., 2006. Finite element analysis of the spondylolysis in lumbar spine. Bio-

412 Medical Materials and Engineering, 16(5), pp. 301-308.

413 Woolf, A. \& Pfleger, B., 2003. Burden of major musculoskeletal conditions. Bulletin of the

414 World Health Organization, Volume 81, pp. 646-656.

415 Yamamoto, I., Panjabi, M., Crisco, T. \& Oxland, T., 1989. Three-dimensional movements of 416 the whole lumbar spine and lumbosacral joint. Spine, 14(11), pp. 1256-1260.

417 